AUG 311994

OSTI

OAK RIDGE

NATIONAL

LABORATORY

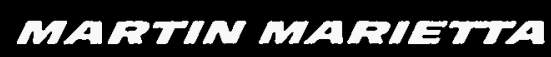

Summary Report on the Y-12 Sludge Detoxification Demonstration Project
Robert L. Jolley

Paul E. Hollenbeck

John M. Kennerly

Suman P. N. Singh

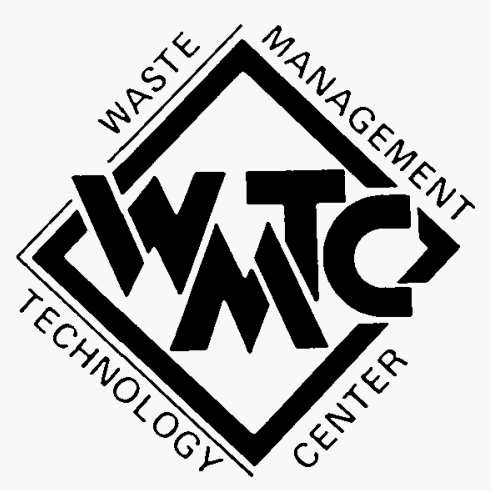

MANAGED BY

MARTIN MARIETTA ENERGY SYSTEMS, INC.

FOR THE UNITED STATES

DEPARTMENT OF ENERGY 
This report has been reproduced directly from the best available copy.

Available to DOE and DOE contractors from the Office of Scientific and Technical Information, P.O. Box 62, Oak Ridge, TN 37831; prices available from (615) 576-8401, FTS 626-8401.

Available to the public from the National Technical Information Service, U.S. Department of Commerce, 5285 Port Royal Rd., Springfield, VA 22161.

This report was prepared as an account of work sponsored by an agency of the United States Government. Neither the United States Government nor any agency thereof, nor any of their employees, makes any warranty, express or implied, or assumes any legal liability or responsibility for the accuracy, completeness, or usefulness of any information, apparatus, product, or process disclosed, or represents that its use would not infringe privately owned rights. Reference herein to any specific commercial product, frocess, or service by trade name, trademark, manufacturer, or otherwise, does not necessarily constitute or imply its endorsement, recommendation, or favoring by the United States Government or any agency thereof. The views and opinions of authors expressed herein do not necessarily state or reflect those of the United States Government or any agency thereof. 


\section{DISCLAIMER}

Portions of this document may be illegible in electronic image products. Images are produced from the best available original document. 
ORNL/TM-11642

Dist. Category UC-510

Chemical Technology Division

Waste Management Technology Center

\title{
SUMMARY REPORT ON THE Y-12 SLUDGE DETOXIFICATION DEMONSTRATION PROJECT
}

\author{
Robert L. Jolley \\ Paul E. Hollenbeck \\ John M. Kennerly \\ Suman P. N. Singh
}

Date Published - July 1994

\author{
Prepared for the \\ Office of Defense Waste and Transportation Management \\ Budget Activity No. GF 0102060
}

Prepared by the

OAK RIDGE NATIONAL LABORATORY

Oak Ridge, Tennessee 37831

managed by

MARTIN MARIETTA ENERGY SYSTEMS, INC.

for the

U.S. DEPARTMENT OF ENERGY

under contract DE-AC05-84OR21400 
ACKNOWLEDGMENTS

$\mathrm{v}$

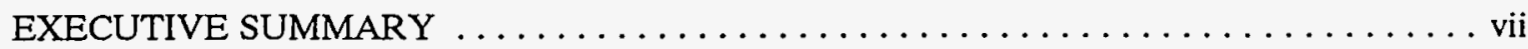

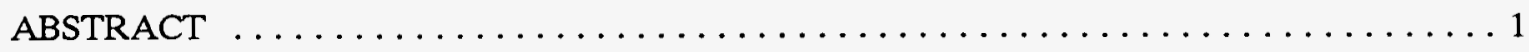

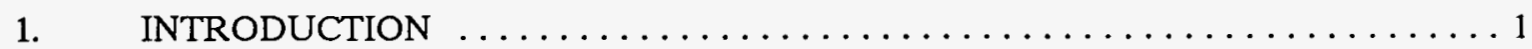

2. DEMONSTRATION ACTIVITIES $\ldots \ldots \ldots \ldots \ldots \ldots \ldots \ldots \ldots \ldots \ldots \ldots \ldots \ldots$

2.1 BACKGROUND AND PURPOSE $\ldots \ldots \ldots \ldots \ldots \ldots \ldots \ldots \ldots$

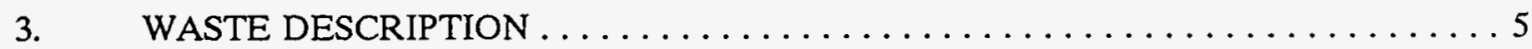

3.1 K-1232-PRODUCED SLUDGE $\ldots \ldots \ldots \ldots \ldots \ldots \ldots \ldots \ldots \ldots \ldots \ldots \ldots \ldots \ldots$

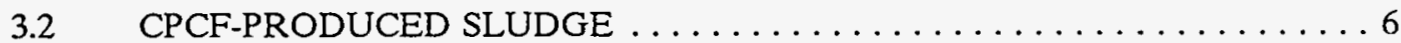

3.3 SELECTION AND BLENDING OF DRUMS $\ldots \ldots \ldots \ldots \ldots \ldots \ldots \ldots$

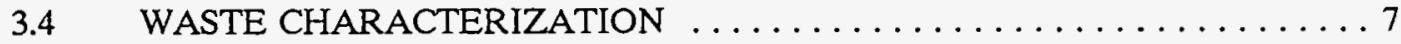

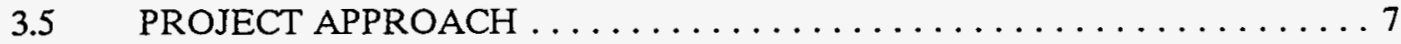

4. X ${ }^{*}{ }^{*}{ }^{2}{ }^{n}{ }^{n}$ SYSTEM DESCRIPTION $\ldots \ldots \ldots \ldots \ldots \ldots \ldots \ldots \ldots \ldots$

4.1 INSTRUMENTATION AND CONTROL $\ldots \ldots \ldots \ldots \ldots \ldots \ldots \ldots$

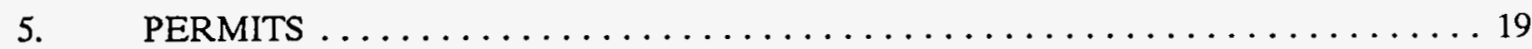

5.1 RESEARCH, DEVELOPMENT, AND DEMONSTRATION

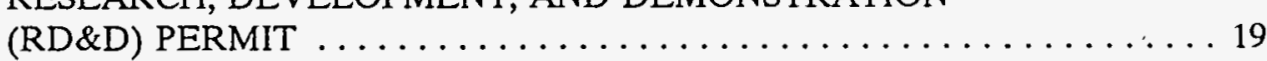

5.2 NATIONAL EMISSION STANDARDS FOR HAZARDOUS

AIR POLLUTANTS (NESHAP) PERMIT . . . . . . . . . . . 19

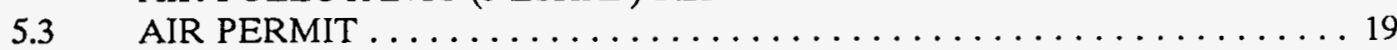

6. BENCH-SCALE TESTING . . . . . . . . . . . . . . . . . . . . . 19

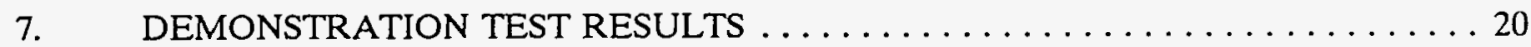

7.1 OPERATIONAL PROBLEMS $\ldots \ldots \ldots \ldots \ldots \ldots \ldots \ldots \ldots \ldots \ldots \ldots \ldots \ldots$

8. EVALUATION OF THE SUCCESS OF THE DEMONSTRATION $\ldots \ldots \ldots 22$

9. BENCH-SCALE SOLIDIFICATION TESTS $\ldots \ldots \ldots \ldots \ldots \ldots \ldots \ldots \ldots \ldots \ldots$

10. CONCLUSIONS AND RECOMMENDATIONS $\ldots \ldots \ldots \ldots \ldots \ldots \ldots \ldots$

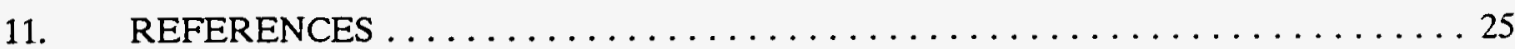


CONTENTS (continued)

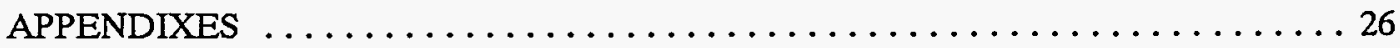

A.1 K-1232 SLUDGE CHEMICAL DATA SUMMARY $\ldots \ldots \ldots \ldots \ldots \ldots \ldots$ A-1

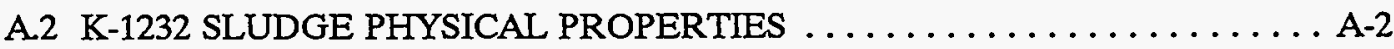

B.1 CPCF SLUDGE CHEMICAL DATA SUMMARY $\ldots \ldots \ldots \ldots \ldots \ldots \ldots$ B-1

B.2 CPCF SLUDGE PHYSICAL PROPERTIES . . . . . . . . . . . . B-2

C STATUS OF SLUDGE AND WASTE STREAMS LETTER $\ldots \ldots \ldots \ldots \ldots \ldots$ C-1

D Y-12 SLUDGE DETOXIFICATION DEMONSTRATION $\ldots \ldots \ldots \ldots \ldots$ D-1 


\section{ACKNOWLEDGMENTS}

The impetus to use demonstrations for the evaluation of waste technologies stems from the insightful DOE/OR leadership of Bill Bibb and Bill Adams with the able assistance of Bob Sleeman and Mike Jugan. Subsequently, the need for and use of technology demonstrations in the waste management and environmental restoration areas have received increasing national attention. This document reports the results from one of the first large demonstration efforts undertaken.

The authors express their sincere appreciation to all the Martin Marietta Energy Systems, Inc., staff (especially those from the Oak Ridge Gaseous Diffusion Plant) who spent many long hours to ensure the success of the demonstration. Much was learned in the course of the demonstration, and even though the Central Pollution Control Facility sludge processing run had to be aborted due to equipment malfunction and limited funding, the overall demonstration should be rated a success.

We appreciate the professional and efficient manner in which the demonstration was conducted by Chem-Nuclear Systems, Inc. (now Rust Remedial Services, Inc.). We especially appreciate the final report from Rust Remedial Services, Inc., concerning the Y-12 Sludge Detoxification Demonstration, which is included as an Appendix. Walter A. Paulson, Jr., the Senior Project Manager, Rust Remeidal Services, Inc., was very helpful in organizing this report although no funding was available.

Sincere appreciation is also expressed to Carol Proaps and Beverly Mathis for typing the report and to Donna Reichle for technical editing of the manuscript. 
( 


\section{EXECUTIVE SUMMARY}

The Y-12 Sludge Detoxification Demonstration was conducted in late 1988 at the Oak Ridge Gaseous Diffusion Plant (subsequently renamed the K-25 Site). The erstwhile Waste Management Technology Center (WMTC) managed the conduct of this waste treatment technology to assist the U.S. Department of Energy/Oak Ridge Operations (DOE/ORO) in implementing the DOE Model. This demonstration was the first project selected by the Hazardous Waste Remedial Actions Program (HAZWRAP)(and funded by DOE) in which a private-sector vendor was contracted to demonstrate an innovative treatment process for treating some of the Oak Ridge Site's radioactive mixed wastes to enable their environmentally compliant disposal. Chem-Nuclear Systems, Inc. (CNSI) was the private-sector vendor selected to demonstrate its $X^{*} \operatorname{TRAX}^{\mathrm{n}}$ process. Briefly, the $\mathrm{X}^{*} \operatorname{TRAX}^{\mathrm{n}}$ process consisted of thermally treating the sludge in an inert atmosphere (to remove the volatile components) to yield a dry residue (containing the nonvolatilized sludge components) and condensed liquids. The dry residue can then be immobilized in cementitious matrix for delisting and disposal in an industrial landfill; the condensed liquids can be disposed in, for example, an incinerator.

The two sludges selected for the demonstration were generated at the Y-12 Plant as a result of wastewater treatment operations at the Central Pollution Control Facility (CPCF) and were labeled the CPCF sludge and the K-1232 sludge. These sludges were F-006 listed hazardous wastes containing low-level radioactive constituents such as uranium. The K-1232 sludge consisted of an earlier batch of CPCF sludge that was trucked, dewatered, and stored in Building K-1232 at the K-25 Site, pending environmentally acceptable treatment and disposal.

The objective of the demonstration was to show that the $X^{*}$ TRAX' process could treat the two sludges so that they could be delisted and disposed in a permitted low-level radioactive waste industrial landfill. The demonstration, from equipment setup to demobilization, was conducted from August through November of 1988. During this period, several runs were made on the $\mathrm{X}^{*}$ TRAX $^{\mathrm{n}}$ unit using the above two sludge populations. The $X^{*} T_{R A X}{ }^{x x}$ system was successful in treating the $\mathrm{K}-1232$ sludge. However, due to problems with the off-gas processing system on the unit, the unit was unable to satisfactorily treat the $\mathrm{CPCF}$ sludge. Later examination indicated that the problem was caused by plugging of the off-gas condensers due to condensation of solid organics removed from the sludge in the thermal treatment unit. This was deemed to be a mechanical problem that could be readily corrected. Funding and scheduling problems resulted in termination of the demonstration, demobilization of the equipment from the site, and redirection of the residue stabilization studies. 
This report presents a summary of the sludge detoxification demonstration and also includes the unedited and unabridged version of CNSI's final report on the demonstration (see Appendix D). The demonstration (despite problems with processing the CPCF sludge) was able to show that the DOE Model concept is workable and that the $\mathrm{X}^{*} \mathrm{TRAX}^{\mathrm{n}}$ process could treat the two Y-12 Plant sludges so that they could be delisted and disposed in compliance with the then applicable regulations. 


\title{
SUMMARY REPORT ON THE Y-12 SLUDGE DETOXIFICATION DEMONSTRATION PROJECT
}

\author{
Paul E. Hollenbeck \\ Robert L. Jolley \\ John M. Kennerly \\ Suman P. N. Singh
}

\begin{abstract}
The Sludge Detoxification Demonstration was conducted for the Hazardous Waste Remedial Actions Program (HAZWRAP) by the erstwhile Waste Management Technology Center (WMTC) as part of its responsibilities to assist the U.S. Department of Energy/Oak Ridge Operations (DOE/ORO) in implementing the DOE Model. This was the first technology demonstration project selected by HAZWRAP and involved demonstration by a private sector contractor of its technology for the treatment of mixed waste sludges. These sludges resulted from the treatment of various wastewater streams at the Y-12 Plant. Some of these sludges were subsequently treated at the Oak Ridge Gaseous Diffusion Plant (ORGDP, now the K-25 Site) to enable disposal. The demonstration involved thermal treatment of the sludge to remove water and organics, followed by fixation of a sample of the dried solids in a cement-based grout matrix. The ultimate goal of the project was to develop data to petition the Environmental Protection Agency (EPA) for delisting the stabilized solids under applicable Resource Conservation and Recovery Act (RCRA) regulations thereby permitting the final disposal of the Y-12 Plant wastewater treatment sludges in accordance with applicable environmental regulations.
\end{abstract}

\section{INTRODUCTION}

A demonstration of the Chem-Nuclear Systems, Inc. (CNSI) X*TRAX ${ }^{*}$ Process for the detoxification of mixed waste sludges was conducted at the Oak Ridge Gaseous Diffusion Plant (ORGPD) in late 1988. The objective of the demonstration was to identify suitable treatment technology for processing the mixed waste sludges generated in the treatment of wastewaters at the Y-12 Plant to ensure their disposal in compliance with applicable environmental regulations.

The demonstration project was managed by the Waste Management Technology Center (WMTC) for the Hazardous Waste Remedial Actions Program (HAZWRAP) as part of WMTC's responsibilities in assisting the Department of Energy/Oak Ridge Operations (DOE/ORO) in implementing the DOE Model. This was the first technology demonstration project selected by HAZWRAP under the DOE Model, and it involved the demonstration by a private-sector contractor 
of technology for the treatment of mixed wastes with a view toward the delisting and disposal of the wastes. CNSI, the private-sector contractor, demonstrated its $\mathrm{X}^{*} \mathrm{TRAX}{ }^{\mathrm{nx}}$ process for the treatment of the sludges. CNSI's report on the demonstration is given unedited and in its entirety in Appendix D.

This report, prepared by the WMTC, summarizes the demonstration activities, describes the results of the technology demonstration, and presents conclusions and recommendations on applicability of the technology for the processing of the wastewater treatment sludges and the demonstration's program.

\section{DEMONSTRATION ACTIVITIES}

In consultation with DOE/ORO and HAZWRAP, the WMTC managed the procurement process for the demonstration, and a letter subcontract was placed with CNSI of Columbia, South Carolina, on June 30,1987 , to begin the project.

The demonstration project was initiated with planning and assigning of responsibilities for the project tasks. The primary focus was on (1) initiating the RCRA Research, Development, and Demonstration (RD\&D) permitting activities and (2) preparing the sludge populations to be used in the demonstration. CNSI, Battelle-Columbus (a subcontractor to CNSI for permitting and final report support), WMTC, Energy Systems Environmental and Safety Affairs (ESA), and DOE/ORO regulatory compliance personnel began to develop the RCRA documentation associated with the RD\&D Permit. It was decided that Energy Systems would issue to DOE/ORO for submission to EPA Region IV a Notice of Intent (NOI) to apply for an RD\&D permit. The NOI was developed over a period of about 6 weeks and included a detailed description of the process. The NOI package was delivered in October 1987 to DOE/ORO, and they transmitted it to EPA Region IV and the Tennessee Department of Health and Environment (TDHE) by letter dated November 6, 1987. The EPA advised on December 25, 1987, at a meeting of the Waste Management Advisory Committee that an RD\&D permit would not be required for the demonstration. There were no further efforts made to obtain an RD\&D permit.

The two populations of sludges for the demonstration consisted of 642 drums of sludge from the ORGDP K-1232 Treatment Facility and 406 drums from the Y-12 Central Pollution Control Facility (CPCF). A statistically significant quantity of drums considered to be representative samples from each of the two populations of sludge were randomly selected for processing during the demonstration. The samples, amounting to 60 drums from each population, were based upon a 
sampling and analysis plan developed for the project and issued in October $1987 .^{1}$

To increase the likelihood of "delisting" the treated sludges following the demonstration, the 60 drums from each population of sludge (K-1232 and $\mathrm{CPCF}$ ) were thoroughly blended and analyzed so that a well-characterized, homogeneous material would be available to avoid uncertainties in feed characteristics associated with the variability in using individual containers of feed material. ORGDP initiated the feed preparation procedure in early August 1987, and it was completed in December 1987. Twenty-four drums from each of the populations of blended drums were randomly selected for treatment.

The technology demonstrated involved an innovative combination of thermal treatment of the sludges followed by fixation of a sample of the dried solids in a cement-based grout matrix. A thermal separation process was employed in which the sludges were indirectly heated in an inert atmosphere driving off the volatiles such as water and organic contaminants and leaving behind a dry nonvolatile residue. The volatilized organics were transferred with the nitrogen carrier gas to an off-gas system where they were recovered for further processing. A density separation was then performed on the condensed liquids from the thermal unit to separate the organic from the aqueous phase. It was anticipated that the solidified waste form encapsulating the dry residue could be eventually "delisted" under RCRA protocols thereby permitting ultimate disposal in landfill. Figure 1 is a block flow diagram of the treatment process.

\subsection{BACKGROUND AND PURPOSE}

In September and October, 1988, CNSI and Chemical Waste Management (CWM), acting under subcontract No. 13K-SA911C with Energy Systems, demonstrated a technology for the treatment of certain wastewater treatment sludges. These sludges were generated at the ORGDP $\mathrm{K}-1232$ facility and the Y-12 CPCF. The sludges were a RCRA-listed hazardous waste which was also contaminated with uranium and other trace radioisotopes. As such, it was a "mixed" waste which could not be readily dealt with under current disposal criteria.

The objectives of the demonstration were as follows:

- Produce regulatory documentation required for the proposed on-site demonstration activities.

- Demonstrate technology which could establish a basis for "delisting" under the provisions of the Hazardous and Solid Waste Amendments of 1984.

- Produce information from the demonstration which could establish the cost and performance of the technology demonstrated for the treatment and disposal of Y-12 sludges and similar materials. 
ORNL DWG 94A-355

BLOCK FLOW DIAGRAM SLUDGE THERMAL SEPARATOR

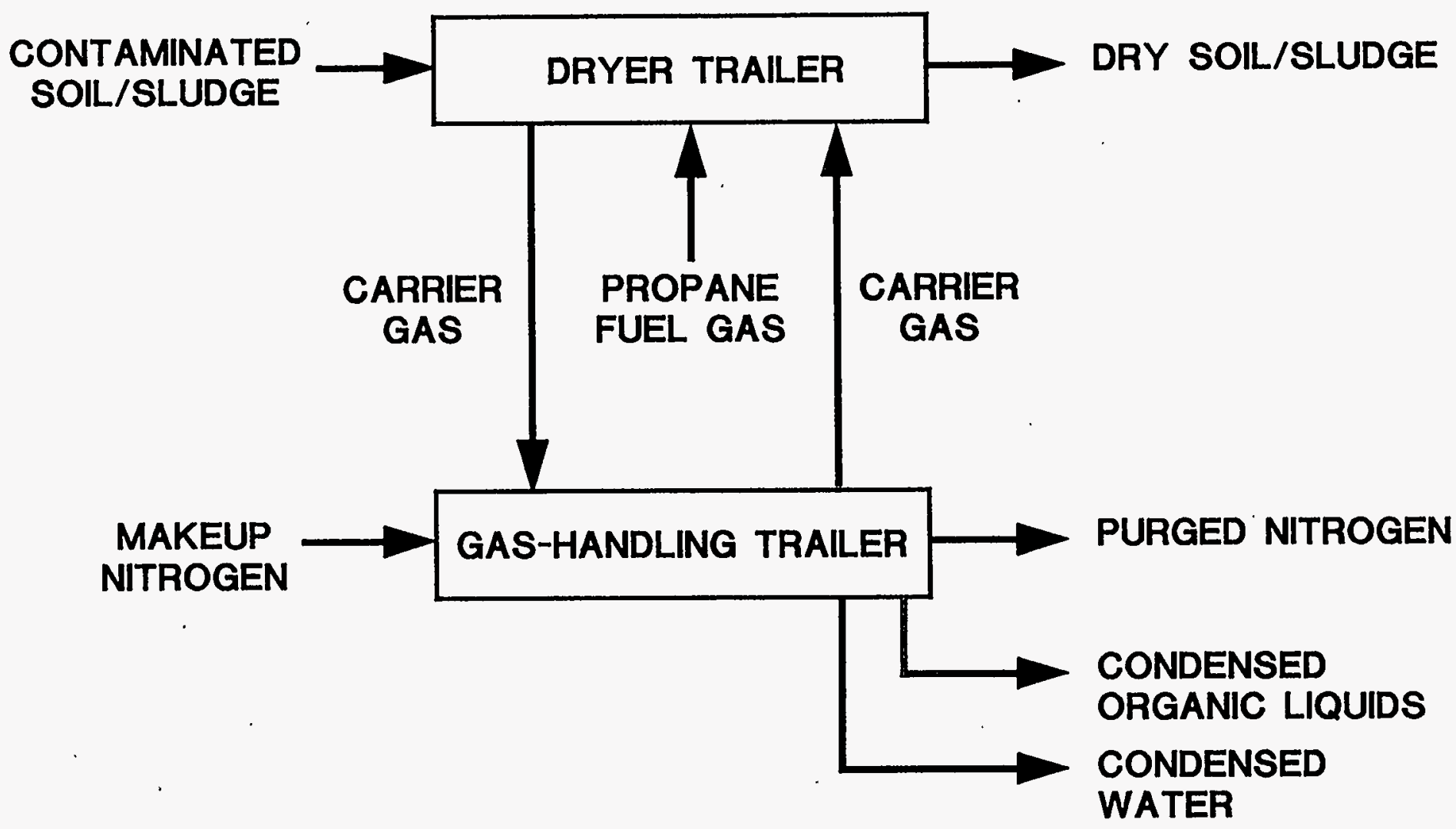

Fig. 1. Block flow diagram of the sludge thermal separator. 
- Communicate with DOE/ORO and other interested parties during the program so that the most benefit could be obtained from the demonstration.

Specifically, the purpose of this demonstration was to apply a technology which, when operated under the proper conditions, would separate the hazardous organic components from the sludge, leaving a dry material which, when stabilized, could be disposed of as a low-level radioactive waste. The organic and aqueous components removed from the sludge would be condensed and collected and could be disposed of by, for example, incineration.

To evaluate the cost-effectiveness and efficacy of the treatment, it was necessary to collect the following data from the treatment demonstration:

- analytical data on the sludges before and after treatment;

- physical characterization data on the sludges before and after treatment (volume, water content, handling data, etc.);

- treatability data;

- $\quad$ costs associated with treatment;

- secondary waste generation as a result of treatment; and

- health physics and industrial hygiene data.

\section{WASTE DESCRIPTION}

The wastes to be treated were sludges resulting from the treatment of non-nitrate liquid process wastes generated at the Y-12 Plant. The sludges were listed hazardous wastes which were also contaminated with uranium and trace quantities of other radioisotopes, such that the sludges were classified as a "mixed" waste. The RCRA listing associated with the sludge was F-006 (i.e., sludges resulting from the treatment of electroplating wastes where cyanides are used in the process).

There were two similar classes of sludges: a CPCF sludge treated at the ORGDP K-1232 facility which contained considerable quantities of organics and a sludge resulting directly from waste treatment at the Y-12 CPCF. The objective of the demonstration was to treat both categories of wastes since both presented similar treatment, storage, and disposal problems. Prior to treatment, the process wastes were primarily wastes from metal finishing operations and a general aqueous waste referred to as "mop waters". The metal finishing wastewaters consisted of acidic and basic wastes, chromate and dichromate wastes, hydrogen fluoride scrubber solutions, and waste containing metals and other proprietary compounds. The "mop waters," or oily wastewaters, contained detergents, oils, and other compounds. These liquids were originally processed at the K-1232 facility at ORGDP (and later at the $\mathrm{Y}-12 \mathrm{CPCF}$ ), where the primary treatment steps were carbon adsorption, $\mathrm{pH}$ adjustment, 
chemical precipitation, and clarification. ${ }^{2}$

\subsection{K-1232-PRODUCED SLUDGE}

In the K-1232 treatment process, the Y-12 wastes were collected and trucked to ORGDP where the shipments were chemically treated as individual batches or in combinations of compatible batches in large reaction tanks. The treated batches were discharged to one of two parallel settling lagoons where heavy metals precipitated as sulfates, hydroxides, silicates, phosphates, or sulfides. Solids that settled in the lagoons were later processed in a scroll-type centrifuge, which produced the semisolid waste now stored in the approximately 550 drums at ORGDP. ${ }^{2}$

The physical and chemical properties of the drummed centrifuge cake from $\mathrm{K}-1232$ varied from (Appendix A.1) drum to drum. In general, the sludge was an extremely thick, hard-to-handle material, with a high solids content and extremely high viscosity (Appendix A.2). It had physical characteristics similar to modeling clay and was more viscous than toothpaste. The sludge was thixotropic, that is, it got thinner or less viscous as it was stirred or agitated. This material could be pumped using high-solids, progressive-cavity pumps. ${ }^{2}$

\subsection{CPCF-PRODUCED SLUDGE}

In the treatment scheme used at the Y-12 Plant, liquid wastes were transferred to CPCF in tankers and other portable containers. The processing or treatment plan for a batch of waste generally consisted of a series of unit operations compatible with the specific batch of waste to be treated. These unit operations could include the following physical and/or chemical processes: neutralization, precipitation, flocculation, chromate reduction, settling, liquid-liquid extraction, filtration, and carbon adsorption. Both a rotary vacuum filter and a filter press were available for filtration. The solids coming off these two units were gravity fed into double-plastic-lined, DOTapproved $17 \mathrm{HH}, 55$-gal drums. The plastic liners and drums were then sealed and the drums manifested and shipped to ORGDP for storage. ${ }^{2}$ Chemical and physical properties of the CPCF sludges are presented in Appendixes B.1 and B.2.

\subsection{SELECTION AND BLENDING OF DRUMS}

As described above, the wastes varied from drum to drum and from population to population in terms of their physical and chemical characteristics. In support of the demonstration, Energy Systems statisticians developed a plan to statistically select a number of drums from each population which, when blended, would provide a sludge mixture that would be representative of a mixture obtained if the entire population of drums were combined. ${ }^{1}$ Once the representative drums were selected from each population, they were each emptied and the material was blended as a batch to 
produce a homogeneous waste. These were chosen to be the feed materials for the demonstration.

\subsection{WASTE CHARACTERIZATION}

To obtain the data necessary to support a delisting petition and to evaluate the success of the demonstration, it was necessary to fully characterize each waste population before and after treatment. After blending, the two populations were sampled and analyzed under a specific sampling and analysis plan. ${ }^{1}$ The data collected as a result of this initial characterization effort indicated that the blending process yielded two very homogeneous populations. The characterization also served to prove that the two populations were distinctly different in terms of their chemical and physical properties. This information was used in establishing the baseline operating parameters for the treatment equipment. Table 1 summarizes the analytical data on the two feed sludges.

\begin{tabular}{||l|l|l||}
\hline \multicolumn{3}{||c|}{ Table 1. Feed sludge analysis summary } \\
\hline & $\mathrm{K}-1232$ & $\mathrm{CPCF}$ \\
\hline Total solids (wt \%) & 29.0 & 40.3 \\
\hline Density (g/mL) & 1.16 & 1.21 \\
\hline Oil and grease (\%) & 2.4 & 25.2 \\
\hline Phenol (ppm) & 22,700 & 6,300 \\
\hline Other semivolatiles (ppm) & 3,400 & 2,400 \\
\hline Tetrachloroethene (ppm) & 2.4 & 5.9 \\
\hline
\end{tabular}

\subsection{PROJECT APPROACH}

The demonstration project consisted of thermal treatment of the two populations of waste to separate the organic contaminants from the sludge in order to produce a dry residue as free of organics as possible. The final step consisted of stabilization of a sample of the dry residue in a cementitious mixture.

The dry, treated solid produced would still be considered a listed and characteristic hazardous waste due to the presence of toxic heavy metals. The purpose of stabilization of the sample was to remove the characteristic (toxicity) for which it is considered hazardous. If demonstrated that the characteristic has been removed by performing an Extraction Procedure Toxicity (EP-Tox) Test and the Toxicity Characteristic Leaching Procedure (TCLP) on the stabilized material, then the technology and the finished product are potentially delistable. Representative samples of the thermally treated material were analyzed to establish the absence of organics and the effectiveness of the stabilization 
of the heavy metals. These activities were planned to provide a high level of confidence that stabilization of the treated material would meet the desired performance criteria for the delisting petition and the ultimate disposal of the residue in a landfill as a Class I low-level radwaste.

\section{X*TRAX ${ }^{\text {ix }}$ SYSTEM DESCRIPTION}

The pilot $\mathrm{X}^{*} \mathrm{TRAX}^{\mathrm{*} x}$ system is transportable and consists of two trailers, one containing the thermal separator unit (dryer) and one containing the off-gas handling system (Fig. 2). In the $\mathrm{X}^{*} \mathrm{TRAX}^{\mathrm{x}}$ process, capable of handling 5 tons/d, contaminated soils or sludges are fed into the dryer, which is an indirectly fired rotary kiln ${ }^{2}$ (Fig. 3). Within the kiln, the feed material is heated to 500 $800^{\circ} \mathrm{F}$ in order to volatilize the moisture and the organic contaminants (Fig. 4). The dried solid product is moved by auger from the kiln to the product tote bins (Fig. 5). Nitrogen carrier gas is circulated through the kiln to transport the volatilized constituents to the off-gas handling system where they are condensed, separated, and collected for further treatment and disposal. Because the kiln is indirectly fired, the products of combustion do not mix with either the waste or the volatilized organics. This reduces the size and complexity of the off-gas handling system. Furthermore, the relatively low temperature and inert carrier gas prevent undesirable chemical reactions of the organic contaminants such as coking. The carrier gas entraining the volatilized materials is treated in a threestage cooling and condensing train to remove the organic materials. The carrier gas exits the dryer at $400-600^{\circ} \mathrm{F}$ and enters the spray tower where it undergoes adiabatic cooling and is cooled to approximately $170^{\circ} \mathrm{F}$. This step removes essentially all of the particulate carryover, along with the organics (See Fig. 2; the off-gas handling system is shown in the background). 


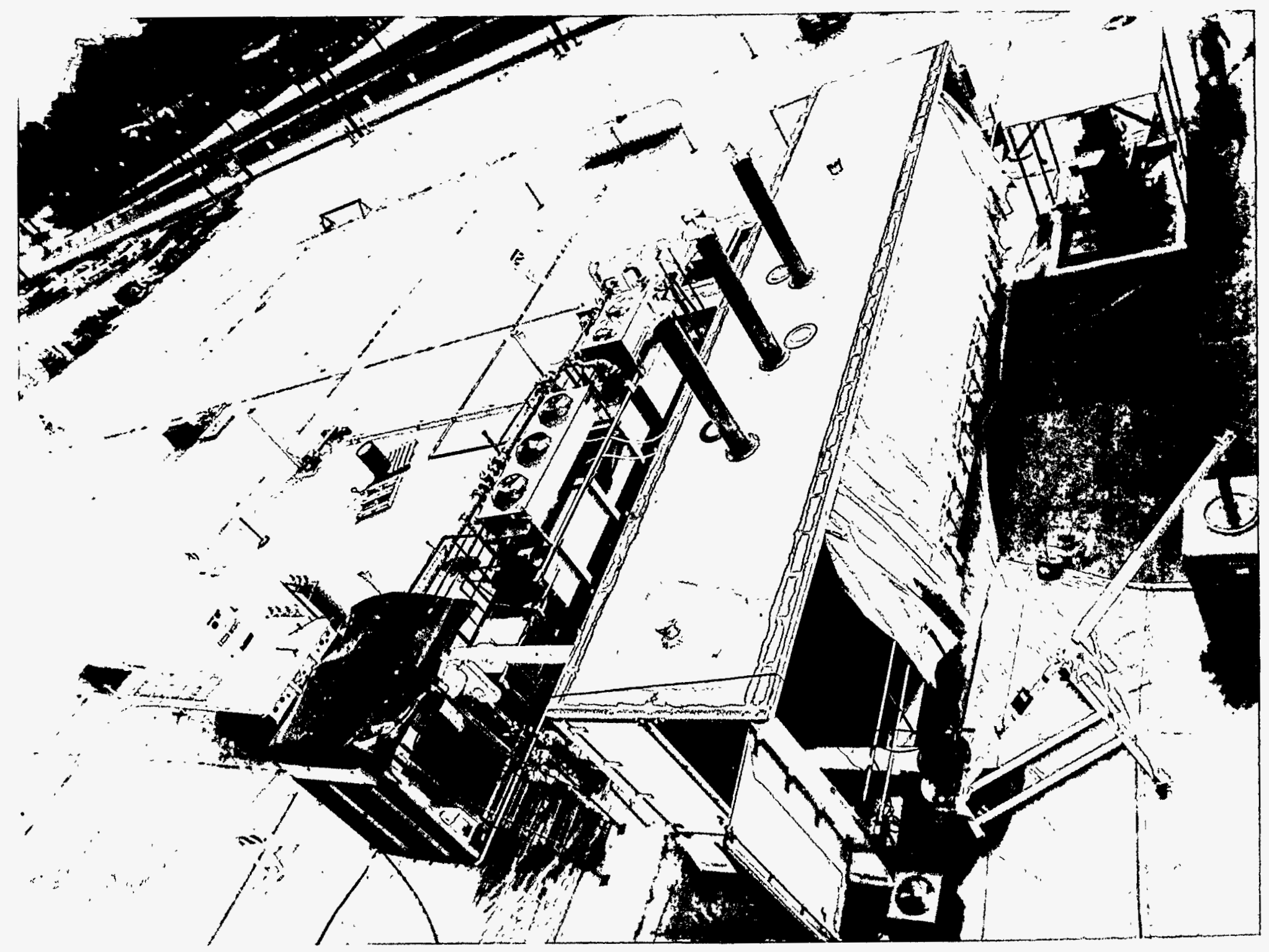

Fig. 2. The thermal separator unit (dryer) is on the trailer (with curtain) with the sludge loading unit (right top) and treated sludge discharge (left bottom). The off-gas handling system and cooling system are behind the dryer to the left of the dryer trailer. 


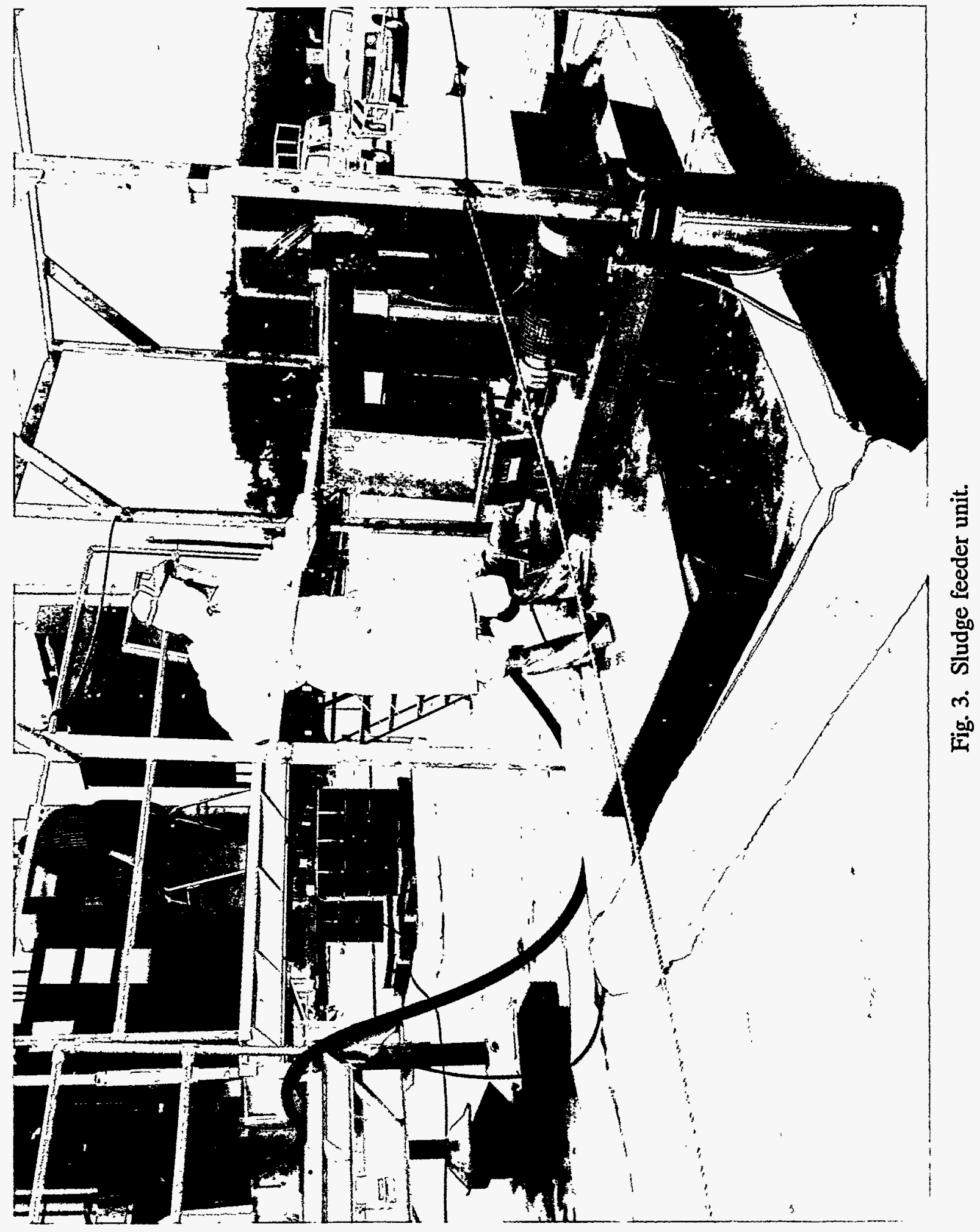




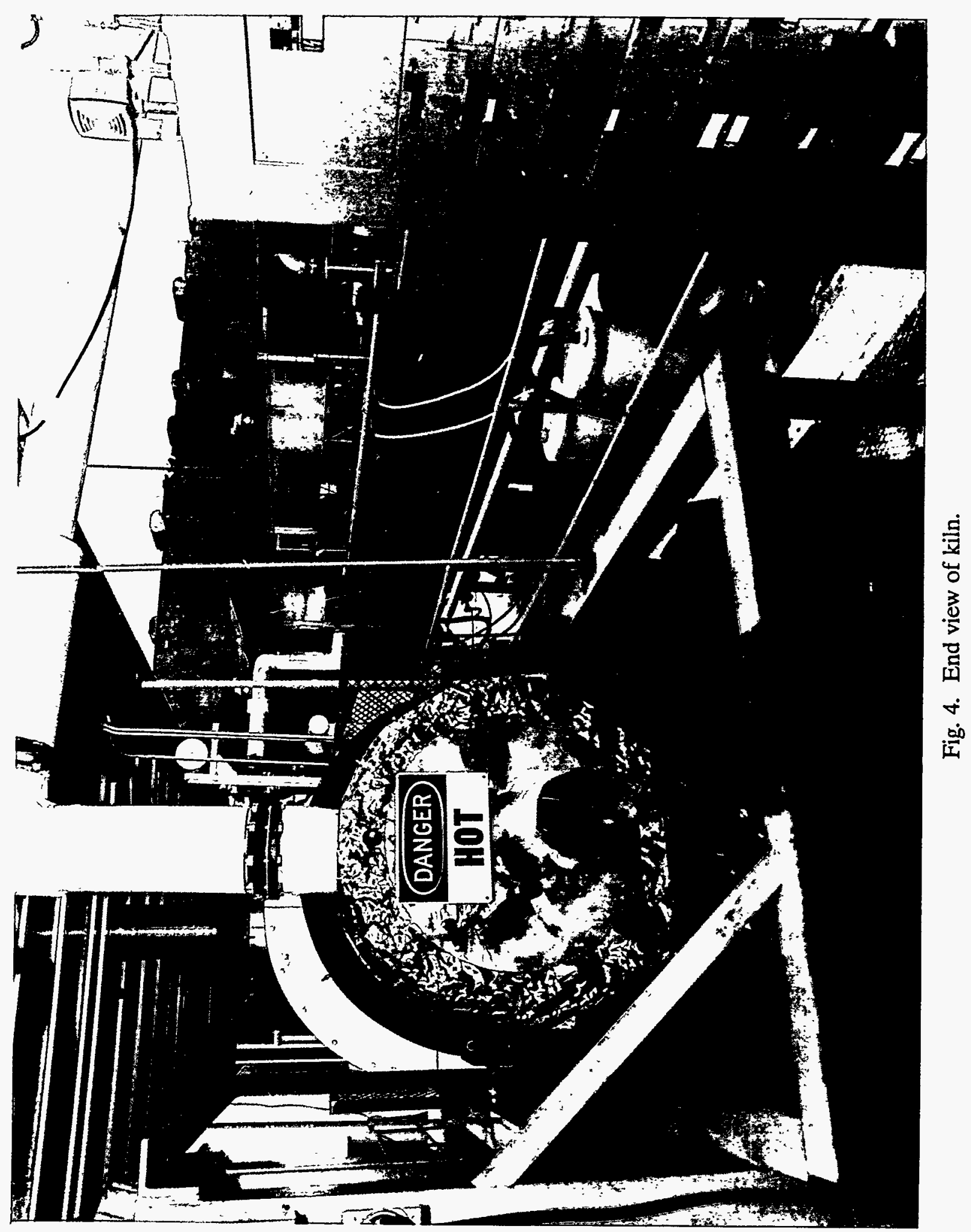




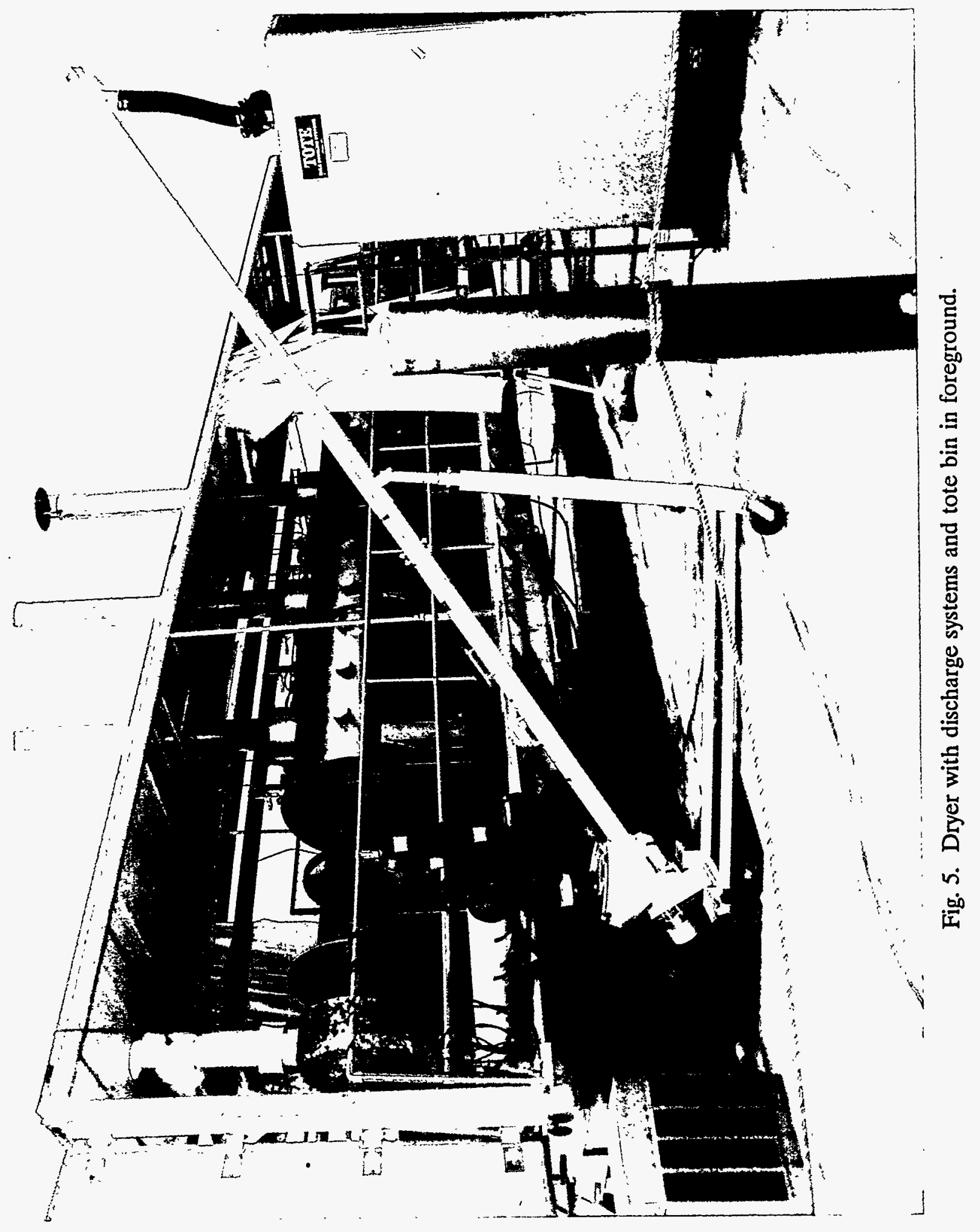


The cooled water-saturated carrier gas exits the spray tower and is further cooled to $80-120^{\circ} \mathrm{F}$ in a shell-and-tube heat exchanger where the major fraction of the water vapor and the intermediate and low-volatility organic components are condensed and removed.

The carrier gas then undergoes further cooling to less than $40^{\circ} \mathrm{F}$ in a second shell-and-tube heat exchanger. This condenses essentially all of the remaining organics and most of the residual water vapor. The carrier gas is then reheated with an electric induction heater to raise the temperature above the dewpoint prior to the blower. The blower transfers the carrier gas through a propane-fired reheater where it is heated and returned to the dryer. The carrier gas flow rate is approximately $100 \mathrm{scfm}$.

The only gaseous release points for the process are a low-flow vent stream which is discharged to the atmosphere. Prior to discharge, this stream is passed through a $5-\mu \mathrm{m}$ filter and a carbon adsorption drum to remove any breathing losses from the collection tanks. The vent stream flows at 1-10 scfm. Its purpose is to maintain low oxygen concentration in the carrier gas. These vented gases consist primarily of nitrogen, water, oxygen, and trace organics.

Water and organics that are condensed in the spray tower are separated in an inclined plate oil/water separator. The water phase is in large part reused for cooling in the spray tower. Condensed organics from the two heat exchangers are collected at the top of the condensate tanks. Any surplus water that is generated by the system may require subsequent treatment external to the gas-handling trailer. Provision for this treatment, other than storage capacity, was not part of the system design (Fig. 6).

The organic liquids that are condensed and collected will similarly require further treatment (such as incineration) external to this system (Fig. 7). A provision is also included to blow down accumulated sludges from both the plate separator and the storage tanks. The treatment of these sludges will be either by reprocessing as feed to the dryer or by alternative processing external to the system, depending on the composition of the recovered sludges. 


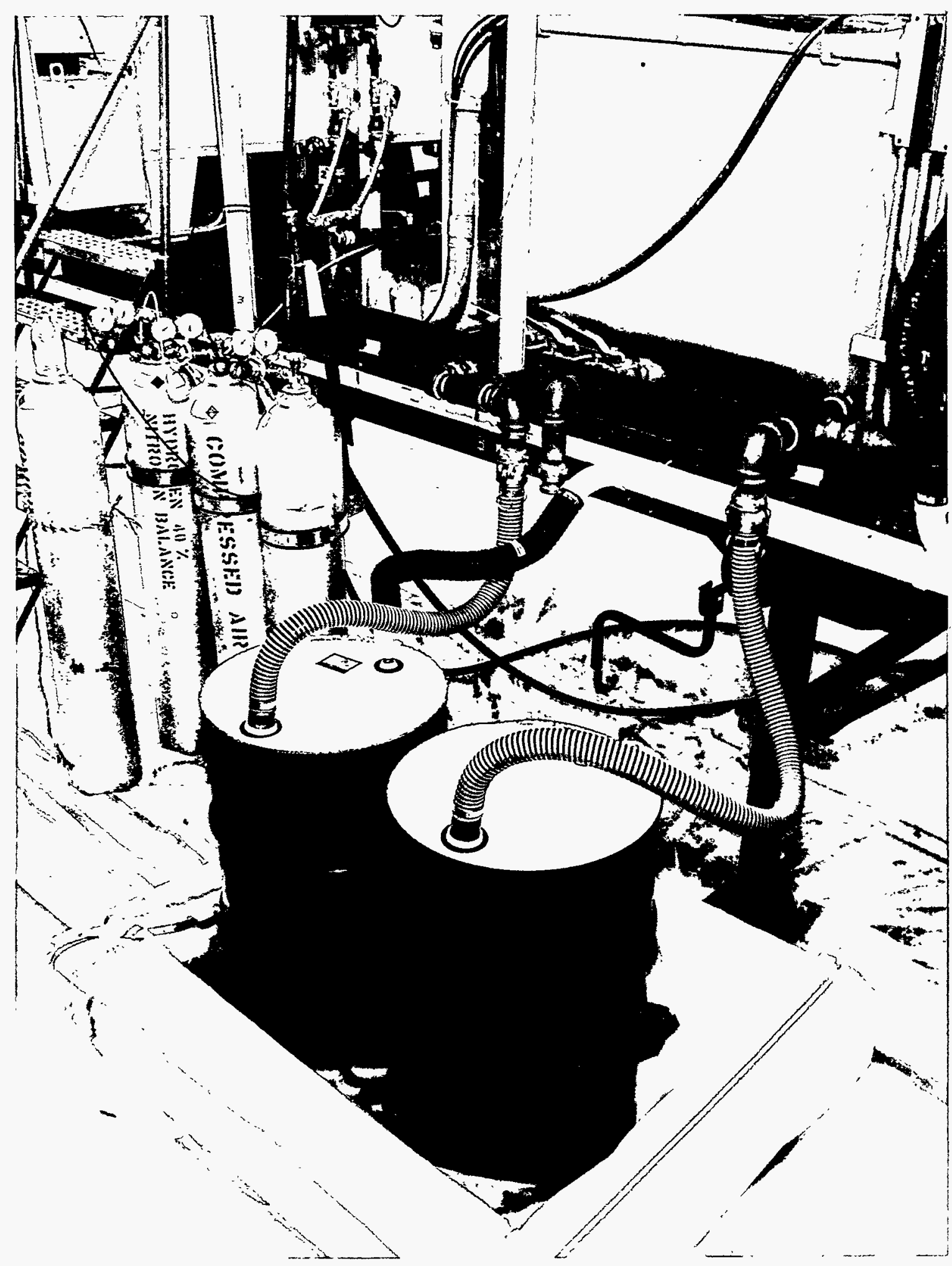

Fig. 6. Surplus water was stored in drums after removal from the systems. 


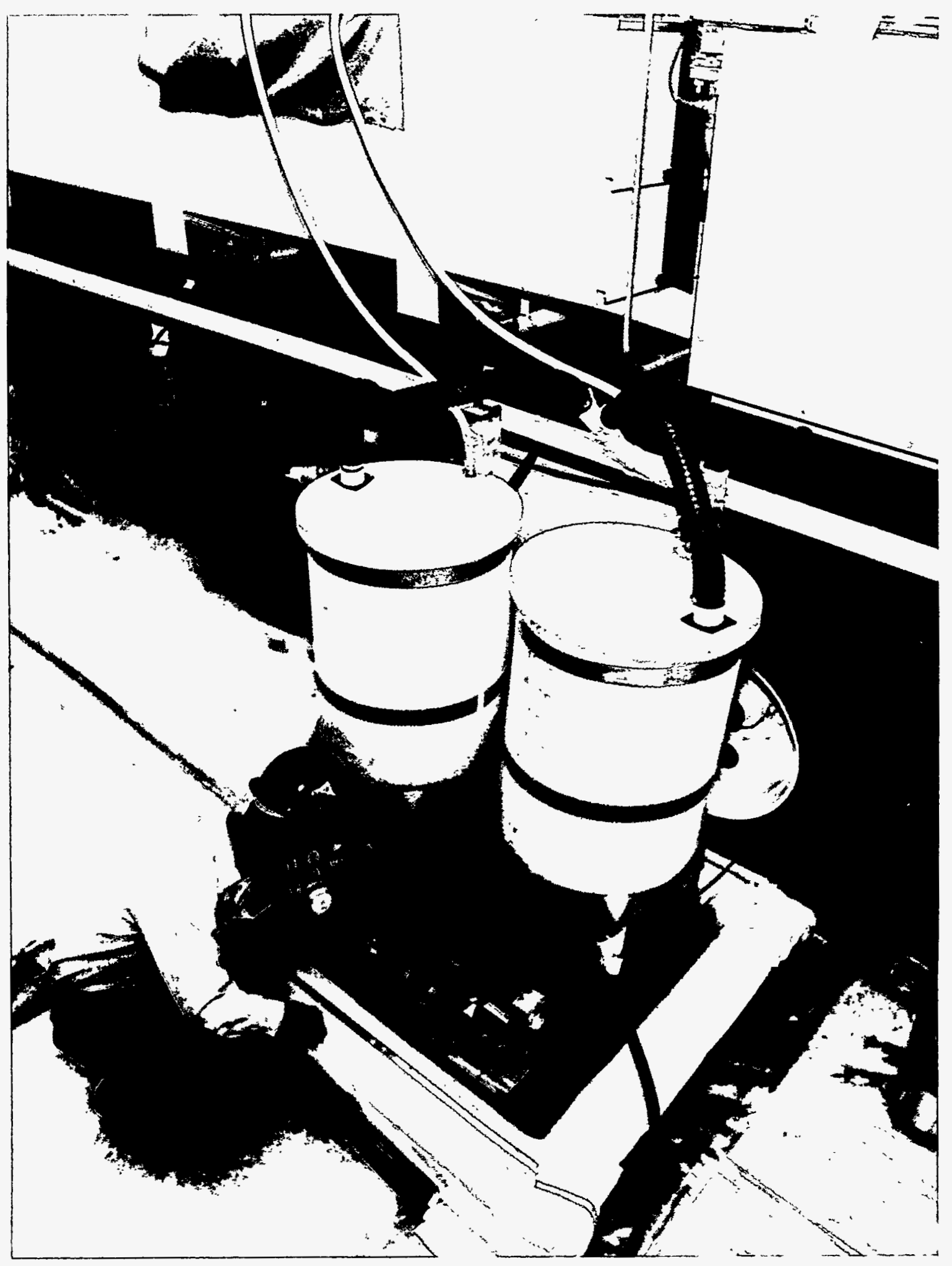

Fig. 7. Condensed organic liquids are collected in plastic drums. 


\subsection{INSTRUMENTATION AND CONTROL}

Control of the $\mathrm{X}^{*} \mathrm{TRAX}^{\mathrm{x}}$ pilot unit is accomplished with a combination of automatic, remote-manual, and manual controls . Each trailer has a control panel to house panel-mounted indicators and controls (Figs. 8 and 9). The burner controls for both the indirectly fired kiln and the carrier gas reheater were provided by the kiln manufacturer and utilized standard combustion control technology. Carrier gas recirculation rate and dryer internal pressure are controlled using modulating valves. The remaining process parameters, such as coolant flow rates and intermediate temperatures, are manually controlled. Temperature, pressure, and flow indicators are provided so that the manual control valves can be set appropriately.

The kiln is maintained at a slight vacuum to preclude leakage out of the system. This is done with a pressure control loop that modulates the vent flow rate to ensure suction at the kiln from the off-gas blower. The recirculation flow to the kiln is also controlled by an automatic controller. High and low pressure in the kiln are annunciated to alert the operator of upsets.

Oxygen concentration in the system is maintained below the combustibility limit ( 7 vol \%) by the continuous $1-10 \%$ vent stream. Makeup nitrogen is added to balance this vent. The oxygen concentration is continuously monitored with an on-line analyzer. This analyzer has two alarm outputs: a high oxygen alarm and a high-high alarm. Initially, the high-alarm is set at $4 \%$ and the high-high at $7 \%$. If oxygen concentration rises above the high alarm setpoint, a supplemental 5- to 10-cfm nitrogen stream is automatically introduced to the kiln discharge breech to help reduce the oxygen level. This will cause the vent controller to simultaneously increase vent flow to compensate for this input. Also, an alarm for high oxygen concentration annunciates to signal the operator. If the supplemental nitrogen and operator attention fail to control the oxygen ingress and oxygen concentration continues to increase above the high-high oxygen concentration alarm, the panel will annunciate to signal required shutdown. Simultaneously, a high-flow nitrogen stream is introduced to the kiln breech at $30 \mathrm{cfm}$, in addition to the supplemental and makeup nitrogen already being introduced to the system. This will act to blanket the system and allow orderly shutdown. The waste feed to the kiln is shut off when the high-high oxygen alarm is activated.

Either high or low temperature in any of the kiln's three burner zones will cause annunciation on the dryer trailer control panel and automatic reset of the burners to low fire. An emergency high temperature will cause the burners to shut down.

The loss of flow in the spray tower water spray line causes annunciation to signal required operator attention. A high temperature on the kiln product discharge or feed breech vent will also annunciate to signal required operator attention. 


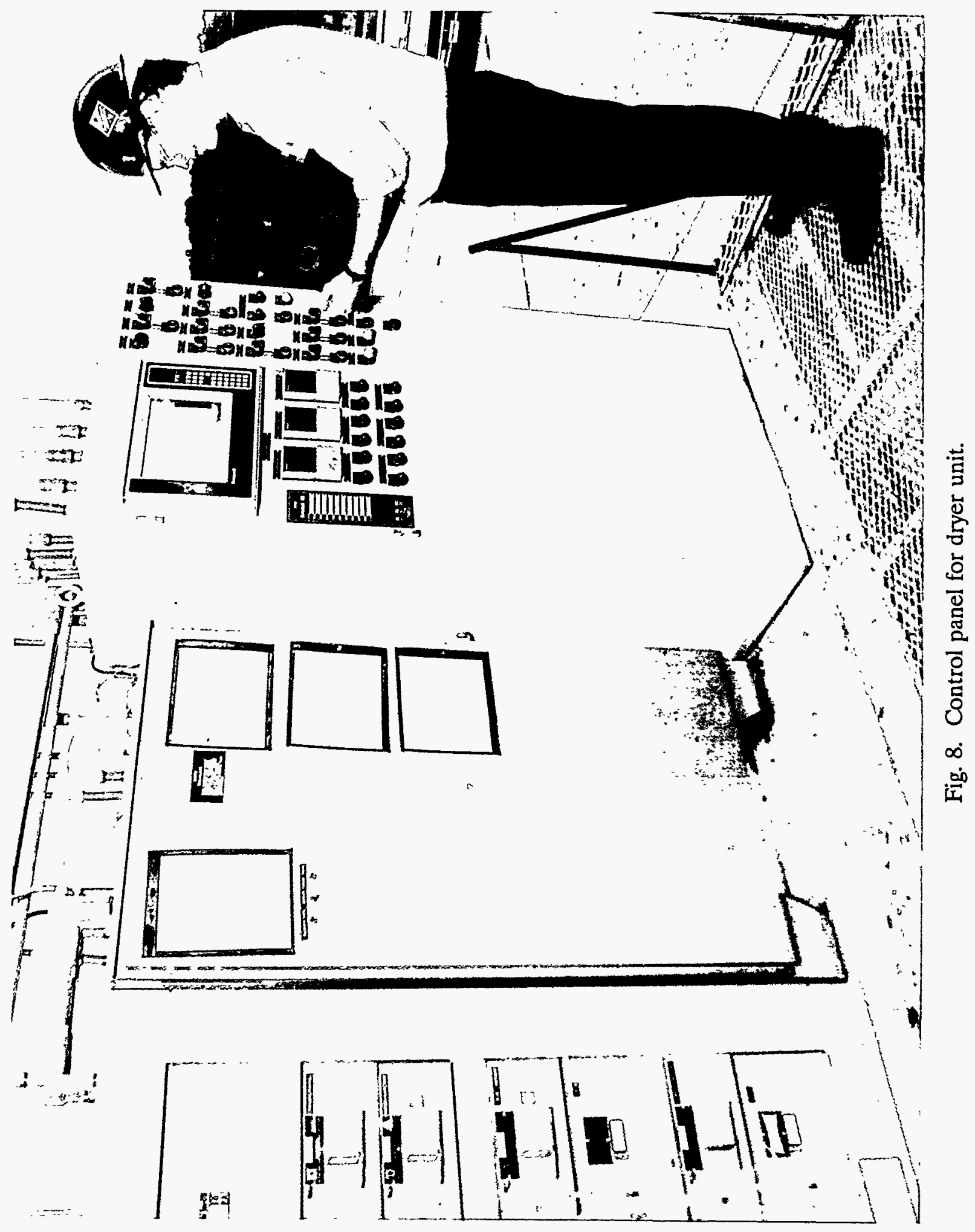




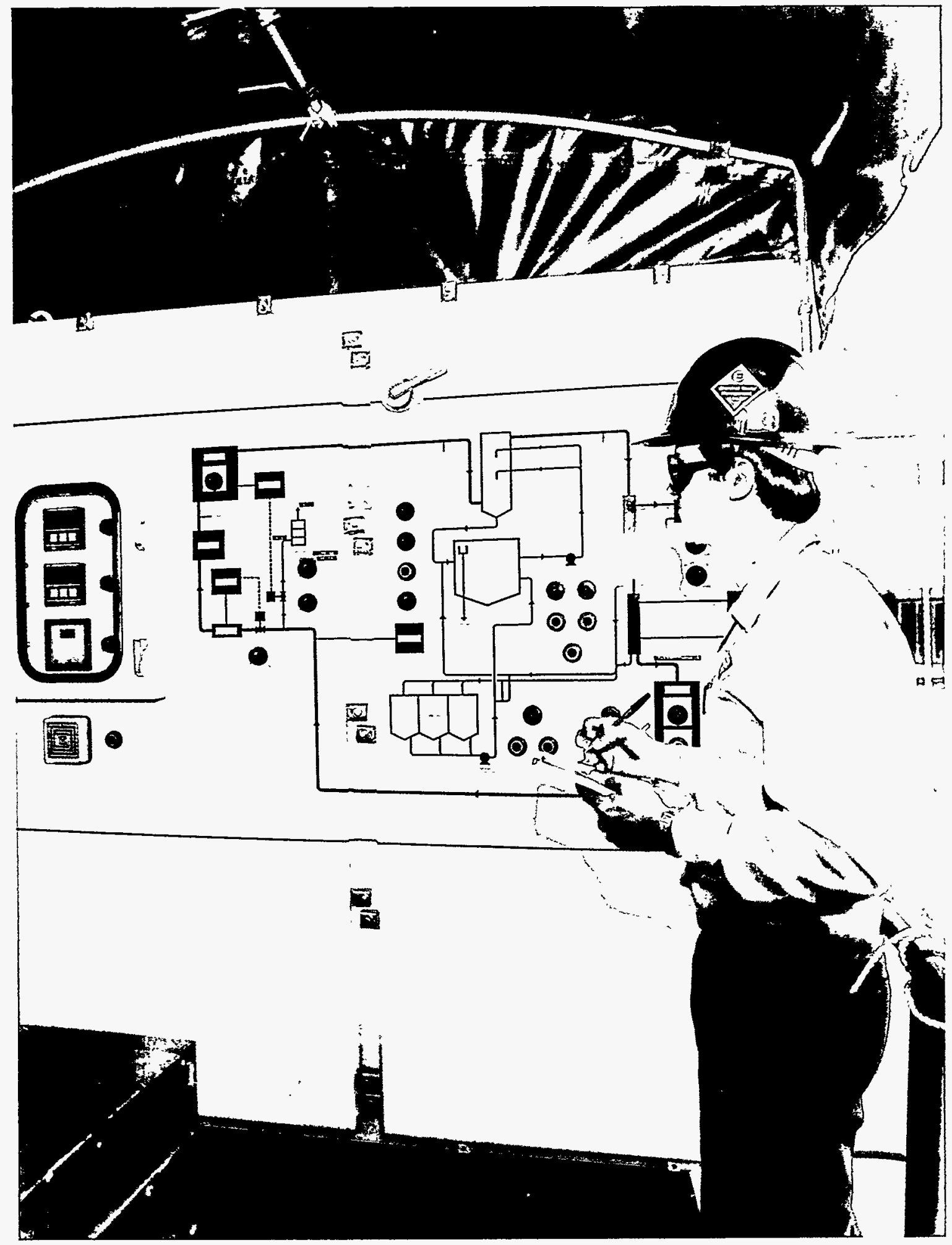

Fig. 9. Control panel for cooling and off-gas systems. 
An inline organic vapor analyzer is installed in the vent piping to provide continuous monitoring of atmospheric emissions. This instrument will give a clear indication in the event of a breakthrough in the vent's carbon adsorption unit.

\section{PERMITS}

\subsection{RESEARCH, DEVELOPMENT, AND DEMONSTRATION (RD\&D) PERMIT}

The demonstration was intended to be conducted as a Research, Development, and Demonstration (RD\&D) project in compliance with the requirements of 40 CFR 270.65. A draft notice of intent was prepared and submitted to Region IV, U. S. Environmental Protection Agency (EPA). Upon receipt of the notice and after discussions with EPA, it was decided that the demonstration could be conducted under a modification to K-25 Site interim status. The request for this modification was submitted by DOE and approved by the TDHE.

\subsection{NATIONAL EMISSION STANDARDS FOR HAZARDOUS AIR POLLUTANTS (NESHAP) PERMIT}

Due to the mobile nature of the demonstration equipment, the relatively short duration of the project, the low content of uranium present in the feed material, and the engineering design of the equipment to preclude particulate emissions, Energy Systems and DOE decided to request a waiver from NESHAP.

\subsection{AIR PERMIT}

An air permit was required because of emissions resulting from the combustion of the propane gas used in heating the kiln and reheating the carrier gas. The application for this permit was prepared and submitted to TDHE. The approved permit application was received from TDHE prior to beginning the demonstration.

\section{BENCH-SCALE TESTING}

Prior to the performance of the demonstration, some preliminary drying and solidification studies were performed at the bench scale. For these studies, approximately $100 \mathrm{~g}$ of each sludge was placed in steel tubes and heated in a laboratory oven under a nitrogen purge. The heating time and temperature were such that they simulated typical $X^{*}$ TRAX $^{\mathrm{Nx}}$ operating conditions. The resulting 
dried material was then solidified in two different mix ratios with CNSI's portland cement formulation. All four solidified samples were then submitted for EP toxicity analysis and ANSI 16.1 leach testing. All samples had lower EP toxicity concentrations than materials that would be considered to have the RCRA characteristic of toxicity. Also, the ANSI 16.1 leach index for all of the samples exceeded the value required for land disposal of low-level radwaste as given in the NRC's position paper on waste form. ${ }^{3}$ These results were encouraging, showing that the basic process steps were successful at the bench scale. $^{3}$

\section{DEMONSTRATION TEST RESULTS}

All 24 drums of the K-1232 sludge, totaling $10,700 \mathrm{lb}$, were successfully processed with the $\mathrm{X}^{*}$ TRAX system according to the project plan (Appendix C, Attachment 1). The average feed rate during the K-1232 production run was $240 \mathrm{lb} / \mathrm{h}$. The pilot system's design feed rate was $420 \mathrm{lb} / \mathrm{h}$ at $30 \%$ moisture, which equated to $126 \mathrm{lb} / \mathrm{h}$ of water. Water evaporation was a rate-limiting parameter for the $\mathrm{X}^{*} \mathrm{TRAX} \mathrm{X}^{\mathrm{m}}$ process. Because the $\mathrm{K}-1232$ sludge contained $70 \%$ moisture, $168 \mathrm{lb} / \mathrm{h}$ of water were fed. This rate was $30 \%$ higher than the design value. The gross heat input was 1.1 million $\mathrm{Btu} / \mathrm{h}$, also well above the design value. ${ }^{4}$

The CPCF parameter-setting run was aborted after processing a little over one drum of material because of the buildup of crystalline organic material that plugged the gas-handling system (Appendix C, Attachment 2). The CPCF and K-1232 materials were quite different. Although the feed analysis indicates that the total solids were higher for the CPCF sludge ( $40.3 \%$ vs $29 \%$ ), the material was very fluid and flowed out of the drums, unlike the pasty K-1232 sludge. Also, the oil and grease content was much higher at $25.2 \%$, which was above the $\mathrm{X}^{*} \mathrm{TRAX}^{\mathrm{w}}$ design level of $10 \%$ total organics. After the run, both white needlelike crystals and a gelatinous sludge were found in the gas system's heat exchangers and condensate traps. The exact cause of the fouling was not determined. Although it was thought that the fouling problem could be solved with equipment design changes, it was decided that no further attempt to run this material would be made due to project item and budget restraints.

The available analytical results for the various runs are summarized in Table 2. The K-1232 product was of such a quality that a high degree of confidence existed that, once stabilized, the material would be a likely candidate for delisting. Analysis of the available product from the $\mathrm{X}^{*} \mathrm{TRAX}^{\mathrm{Nx}}$ processing of the CPCF sludge indicated that stabilization of this material would also likely produce an acceptable product. Residue waste stream information is provided in Appendix C, Attachment 3. 


\begin{tabular}{|c|c|c|c|}
\hline \multicolumn{4}{|c|}{$\begin{array}{l}\text { Table 2. Analytical results of the dry treated residues from the } \mathrm{X}^{*} \mathrm{TH} \\
\text { unit } \\
\text { Removal efficiency (\%) }\end{array}$} \\
\hline Sludge source & Solids (wt \%) & Oil and grease & Phenol \\
\hline $\mathrm{K}-1232$ & 99.95 & 85.8 & 99.6 \\
\hline CPCF & 98.8 & 74.4 & 92.9 \\
\hline
\end{tabular}

The process vent stream was closely monitored for radioactive emissions. With the addition of a HEPA filter in the vent line, all applicable standards were met. Also, no detectible volatile organic compounds were found in the system process vent stream. Analysis of the condensed water showed that the radioactivity was below drinking water standards. This water could be processed through the existing water treatment plant at Y-12. The sludge from the gas system's phase separator did contain measurable radioactivity because it contained solid particulate from the feed material. The phase separator sludge could be incinerated on-site. ${ }^{4}$

A significant reduction in the organic content of the CPCF sludge was made in the aborted parameter-setting run. It appeared from the product analysis that the treated CPCF material was also a good candidate for stabilization. Reworking the design of the gas-handling system to accommodate the quantity and types of organic contaminants would probably have allowed the $X^{*} T R A X^{\pi x}$ process to be effective for the CPCF sludge. ${ }^{4}$

For both sludges, oil and grease removal was approximately $75-85 \%$. It was impossible to relate this removal to expected system performance on other materials because oil and grease is a gross measure and does not account for the specific organic materials present. Phenol removal of $93 \%$ to $99.6 \%$ indicated good desorption. ${ }^{4}$

\subsection{OPERATIONAL PROBLEMS ${ }^{4}$}

During the course of the demonstration, several mechanical problems were experienced that delayed the start of waste processing. These problems and their respective resolutions were:

- $\mathrm{O}_{2}$ analyzer failure - The instrument that monitors the oxygen concentration in the recirculating gas stream failed, probably due to moisture in the sensor head. The circuit board and sensor were replaced, and the sensor head was sealed.

- Organic analyzer failure - The flame ionization analyzer that monitors the organic concentration in the process vent required periodic cleaning. Cleaning was completed as needed. 

replaced under warranty. The failure cause was undetermined.

0 Moyno ${ }^{\text {ix }}$ pump failure - The feed system's Moyno ${ }^{\text {ix }}$ pump stator degraded, probably due to chemical attack of the stator. The stator's material was the only type that was available on short notice. It was replaced from spare parts.

- Power failure - The main power supply to the $\mathrm{X}^{*} \operatorname{TRAX}^{\mathrm{nx}}$ system was inadvertently shut off. The equipment failed safe and was restarted without incident within $5 \mathrm{~min}$ of restoring power.

Each of these mechanical problems was repaired in $1 \mathrm{~d}$ or less, limiting the total project delay to less than $3 \mathrm{~d}$.

\section{EVALUATION OF THE SUCCESS OF THE DEMONSTRATION ${ }^{3}$}

All required approvals were obtained, and the mixed wastes were processed in accordance with those approvals, without release to the environment.

The thermal separation of the sludge was partially successful, in that all of the K-1232 sludge was processed as planned and appeared to be acceptable for solidification. The CPCF sludge could not be processed with the existing equipment because of the fouling of the condensers with organic materials. It is possible that this could have been anticipated had bench-scale simulations been performed on the condensation operations. However, samples of the sludges could not be sent off-site for evaluation by CNSI and CWM because of the nature of the waste.

A complete analysis of the costs associated with the demonstration was not performed. However, certain aspects of the economics of the treatment were apparent during the demonstration. The high moisture and organic content of the feed greatly increased the unit cost for treatment to well above what would normally be expected for thermal desorption technology. This is primarily because the equipment was operated at reduced capacity because of the high required heat input, and the volume of condensed liquids requiring subsequent treatment or disposal was greater than for the contaminated soils for which the equipment was primarily intended. Also, the mobilization, decontamination, and demobilization costs were distributed over a very small quantity of the sludge treated in the demonstration, giving nonrepresentative costs for a production-scale project. In the final analysis, these costs and the operating costs must be assessed separately. 


\section{BENCH-SCALE SOLIDIFICATION TESTS}

After a hiatus of almost 1 year to resolve the project's funding difficulties, bench-scale tests were performed on samples of the dry residue from the $X^{*} T R A X^{*}$ processing of the sludges. The bench-scale tests consisted of stabilizing the residue in a cementitious mixture and subjecting the resulting waste forms to the EPA's EP-Tox and TCLP leaching protocols. The bench-scale stabilization tests were performed by CNSI personnel in a laboratory at ORGDP using a CNSI proprietary cementitious mixture. The analytical testing of the resulting waste forms containing the residue was performed by the ORGDP Analytical Laboratories. The test results, as reported by Kirkpatrick and Shoemaker, ${ }^{5}$ indicate that (1) the stabilized dry residue passed the requisite leaching procedures and, (2) upon delisting, the stabilized residue could be disposed in an appropriate landfill as a Class I low-level radwaste. 


\section{CONCLUSIONS AND RECOMMENDATIONS}

While the pilot X*TRAX ${ }^{\mathrm{nx}}$ system was not designed for treatment of radioactive material, the unit, with minor field modifications, successfully handled the material treated in this project with no environmental releases and no personnel exposure. Likewise, industrial hygiene monitoring indicated that personnel exposure to volatile organics did not pose a problem. Stack samples taken from the process vent downstream of the activated carbon beds did not indicate the presence of volatile organics.

Although the duration of the operations and the number of sludge drums processed were insufficient to optimize the operating conditions, the system was effective in drying the material and in desorbing a high percentage of the oils and grease and the phenol present in the wastes fed to the unit. In terms of moisture and organic content, the sludges fed to the unit were at or exceeded the design basis of the system and represented the worse-case test of system capabilities. More typical feed materials for a thermal desorption unit naturally contain greater than $60 \%$ solids and less than

$5 \%$ total organics. A review of the cost data indicates that cost-effectiveness decreases as moisture and organic content increase.

In summary, the $\mathrm{X}^{*} \mathrm{TRAX}^{\mathrm{r}}$ system was successful in treating the $\mathrm{K}-1232$ sludge, while mechanical problems were encountered when processing the CPCF sludge. Modification of the off-gas handling system that was made as a result of information gained during this demonstration project will make the process applicable to a broader range of waste sludges and contaminated soils. 


\section{REFERENCES}

1. C. R. Kirkpatrick and J. W. Zolyniak, Sampling and Analyses Project Plan for Waste Characterization, Delisting, and Disposal Activities for the RCRA RD\&D Project to Treat $Y-12$ Plant Low Level Mixed Waste Sludges at the Oak Ridge Gaseous Diffusion Plant, Oak Ridge, Tennessee, K/QT-147, Oak Ridge Gaseous Diffusion Plant, October 1987.

2. D. Padgett and P. E. Hollenbeck, "X*TRAX": An Application for Mixed Waste Separation," pp. 519-23 in Waste Management '89, Vol II (proceedings of Waste Management '89, University of Arizona, Tucson, ed. R. G. Post. 1989).

3. American Nuclear Society, "Measurement of the Leachability of Solidified Low-Level Wastes by a Short-Term Test Procedure," ANSI/ANS-16.1-1986, April 1986.

4. C. R. Palmer and P. E. Hollenbeck, "Sludge Detoxification Demonstration," presented at the 1989 Incineration Conference, May 1-5, 1989, Knoxville, Tennessee.

5. C. R. Kirkpatrick and J. L. Shoemaker, Determination of the Delisting Potential for the Dried Product Produced by the Sludge Detoxification Demonstration Project (X-TRAX) Conducted at the Oak Ridge Gaseous Diffusion Plant, K/QA-346, Oak Ridge Gaseous Diffusion Plant, February 1990. 
APPENDIXES 


\section{A-1}

\section{APPENDIX A.1}

K-1232 Sludge Chemical Data Summary

(Source: Statement of work for the Demonstration of Hazardous

Waste Treatment Technology as applied to Y-12 Plant Mixed Waste Sludges)

\begin{tabular}{|c|c|c|c|}
\hline Parameters & Minimum & $\begin{array}{r}\text { Concentrations in ug/g } \\
\text { Average }\end{array}$ & Maximum \\
\hline Aluminum & 5600 & 29,000 & 54,000 \\
\hline Arsenic & $\langle 5.0$ & 6.4 & 36 \\
\hline Barium & 37 & 101 & 410 \\
\hline Beryllium & 0.46 & 13.5 & 49 \\
\hline Boron & 48 & 368 & 670 \\
\hline Cadmium & $<0.30$ & 13 & 110 \\
\hline Calcium & 140,000 & 203,000 & 310,000 \\
\hline Chromium & 21 & 776 & 2200 \\
\hline Cobalt & 15 & 50 & 92 \\
\hline Copper & 85 & 420 & 870 \\
\hline Iron & 180 & 41,878 & 99,000 \\
\hline Lead & 100 & 197 & 460 \\
\hline Lithium & 7.5 & 71 & 120 \\
\hline Nickel & 1200 & 10,230 & 21,000 \\
\hline Niobium & 9.3 & 44 & 110 \\
\hline Phosphorus & 18,000 & 33,550 & 68,000 \\
\hline Potassium & 7900 & 12,305 & 17,000 \\
\hline Selenium & $<5.0$ & $<5.0$ & $\langle 5.0$ \\
\hline Silver & $<0.6$ & 1.0 & 24 \\
\hline Sodium & 2500 & 11,335 & 29,000 \\
\hline Strontium & 74 & 105 & 120 \\
\hline Thorium & 120 & $<20$ & $<20$ \\
\hline Titanium & 64 & 152 & 200 \\
\hline Vanadium & 0.6 & 6.6 & $n$ \\
\hline Zinc & 180 & 500 & 660 \\
\hline Phenols & 545 & 3816 & 34,631 \\
\hline Cyanide & 0.19 & 1.65 & 3.95 \\
\hline Total Uranium & 316 & 2904 & 5800 \\
\hline
\end{tabular}


A-2

APPENDIX A.2

K-1232 Sludge Physical Properties

(Source: Statement of work for the Demonstration of Hazardous

Waste Treatment Technology as applied to Y-12 Plant Mixed Waste Sludges)

Viscosity

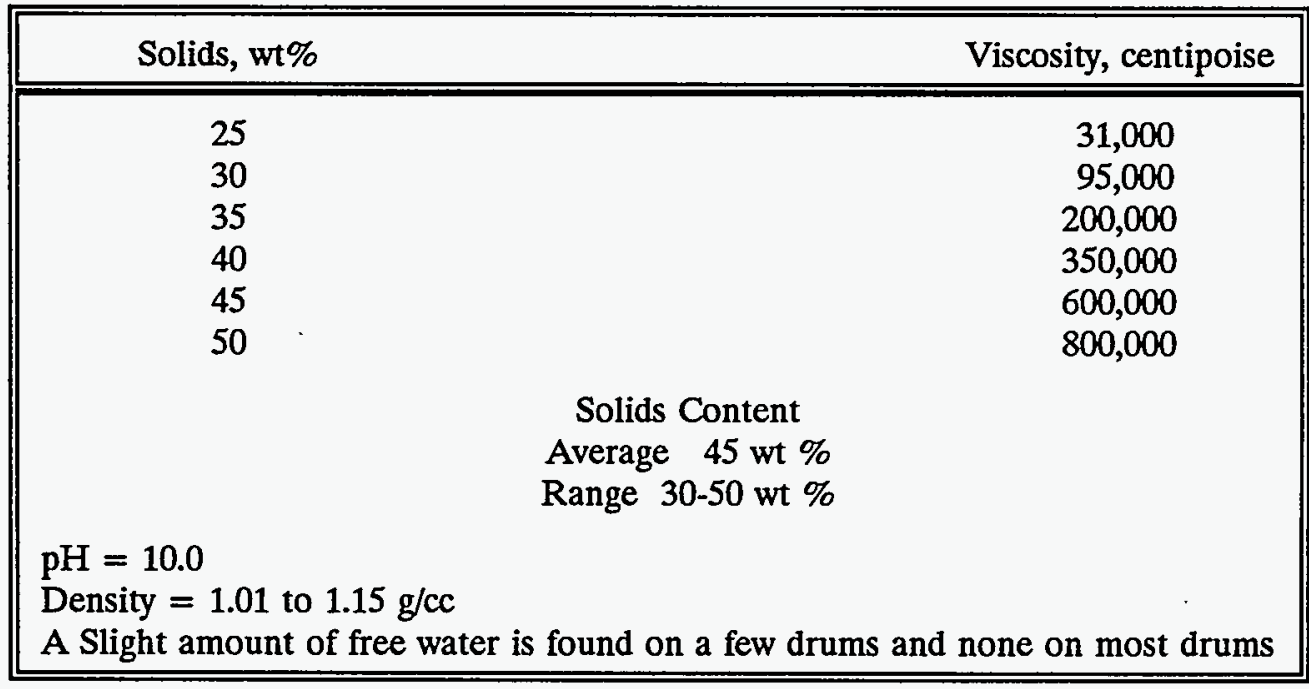




\section{B-1}

APPENDIX B.1

CPCF Sludge Chemical Data Summary

(Source: Statement of work for the Demonstration of Hazardous

Waste Treatment Technology as applied to Y-12 Plant Mixed Waste Sludges)

\begin{tabular}{|c|c|c|c|}
\hline Parameters & Minimum & $\begin{array}{c}\text { Concentrations in ug/g } \\
\text { Average }\end{array}$ & Marimum \\
\hline Aluminum & 420 & 5460 & 25,000 \\
\hline Arsenic & 26 & 5 & 11.7 \\
\hline Barium & 14 & 34 & 61 \\
\hline Beryllium & 0.03 & 45 & 310 \\
\hline Boron & 25 & 57 & 98 \\
\hline Cadmium & 0.3 & 40 & 440 \\
\hline Calcium & 570 & 62,320 & 230,000 \\
\hline Cbromium & 1.0 & 63 & 370 \\
\hline Cobalt & 0.5 & 17 & 40 \\
\hline Copper & 1.6 & 209 & 760 \\
\hline Iron & 1000 & 38,000 & 85.000 \\
\hline Lead & 5 & 125 & 290 \\
\hline Lithium & 0.4 & 7 & 45 \\
\hline Magnesium & 110 & 3016 & 18,000 \\
\hline Manganese & 13 & 367 & 4200 \\
\hline Mercury & 1 & 3 & 17 \\
\hline Molybdenum & 1 & 49 & 130 \\
\hline Nickel & 3.8 & 194 & 810 \\
\hline Niobiums & 0.7 & 66 & 140 \\
\hline Potassium & 69 & 560 & $8 \$ 0$ \\
\hline Selenium & 0.5 & 43 & 20 \\
\hline Silicon & 72 & 300 & 530 \\
\hline Sitver & 0.6 & 0.9 & 1.9 \\
\hline Sodium & 140 & 1308 & 2600 \\
\hline Strontium & 3 & 25 & 110 \\
\hline Titanium & 24 & 100 & 770 \\
\hline Vanadium & 1.3 & 8 & 16 \\
\hline Total Uranium & 4 & 2350 & 8800 \\
\hline Cyanide & 1 & 1 & 217 \\
\hline $\begin{array}{l}\text { Total Organic } \\
\text { Carbon }\end{array}$ & 0.06 & 17 & 44.4 \\
\hline Pbenolics & 0.01 & 140 & 401 \\
\hline
\end{tabular}


B-2

APPENDIX B.2

CPCF Sludge Physical Properties

(Source: Statement of work for the Demonstration of Hazardous

Waste Treatment Technology as applied to Y-12 Plant Mixed Waste Sludges)

\begin{tabular}{||cc||}
\hline \multicolumn{2}{|c||}{ Viscosity } \\
Not Available \\
pH \\
Minimum & 5.6 \\
Maximum & 10.0 \\
Average & 7.7 \\
Wt. \% Solids \\
Minimum & $30 \%$ \\
Maximum & $53 \%$ \\
Average & $40 \%$ \\
Oil and Grease \\
Minimum $\quad 0.10 \%$ \\
Maximum $\quad 30 \%$ \\
Average & $20 \%$ \\
\hline
\end{tabular}


C-1

APPENDIX C

July 31, 1989

D. A. Coleman

Status of Sludge and Waste Streams After the Y-12 Sludge Detoxification Demonstration

The Y-12 Sludge Detoxification Demonstration conducted at K-25 in 1988 involved treatment of selected quantities of two accumulations of drummed and stored sludges. These resulted from Y-12 Plant process wastewater streams which were treated at the ORGDP K-1232 facility (K-1232) and waste streams which came from the Y-12 Central Pollution Control Facility (CPCF).

Sludge from the K-1232 facility totaled 624 drums, from which 54 were randomly selected for the demonstration and were blended together forming 50 new drums. The CPCF sludge amounted to 406 drums, from which 60 were randomly selected for the demonstration and were blended together forming 37 new drums.

A total of 24 drums were then randomly selected for the demonstration from the blended $50 \mathrm{~K}-1232$ drums, and 24 drums were also selected for the demonstration from the blended $37 \mathrm{CPCF}$ drums. Identification of the drums prior to and after blending/mixing are shown on Attachments 1 and 1 to this letter. Attachment 3 provides status and identification of residue waste streams from the demonstration.

The information provided in this letter is for information purposes and future reference.

If you have any questions, please don't hesitate to contact me.

P. E. Hollenbeck, WMTC, K-1037, MS-7357 (4-6629)

PEH:cap

Attachments

cc: $\quad$ T. A. Bowers

R. L. Jolley

S. P. N. Singh

H. D. Whitehead

File (3) 
C-2

ATTACHMENT 1

K-1232 Sludge Blended/Mixed

\begin{tabular}{||r|l|l||}
\hline 1 & 392 & 657 \\
36 & 415 & 664 \\
38 & 418 & 671 \\
47 & 486 & 679 \\
55 & 501 & 688 \\
56 & 524 & 699 \\
99 & 538 & 721 \\
101 & 557 & 726 \\
102 & 560 & 738 \\
108 & 576 & 761 \\
119 & 585 & 763 \\
308 & 592 & 765 \\
310 & 618 & 775 \\
320 & 620 & 795 \\
346 & 635 & 811 \\
352 & 637 & 813 \\
377 & 644 & 822 \\
391 & 651 & 837 \\
\hline
\end{tabular}

K-1232 Sludge After Blending/Mixing CNK 1 through 50

K-1232 Sludge Processed in the Demonstration

\begin{tabular}{||l|l|}
\hline CNK-2 & CNK-29 \\
CNK-4 & CNK-30 \\
CNK-6 & CNK-32 \\
CNK-7 & CNK-34 \\
CNK-12 & CNK-35 \\
CNK-13 & CNK-36 \\
CNK-15 & CNK-38 \\
CNK-16 & CNK-41 \\
CNK-18 & CNK-45 \\
CNK-19 & CNK-46 \\
CNK-23 & CNK-48 \\
CNK-28 & CNK-50 \\
\hline
\end{tabular}

All blended/mixed drums of K-1232 sludge not processed during the demonstration were returned to the vaults for storage. 
C-3

ATTACHMENT 2

CPCF Sludge Blended/Mixed

\begin{tabular}{||l|l|l|l||}
\hline \hline $85-6$ & $86-0070$ & $86-0167$ & $86-0281$ \\
$85-7$ & $86-0080$ & $86-0170$ & $86-0282$ \\
$85-11$ & $86-0081$ & $86-0177$ & $86-0301$ \\
$85-38$ & $86-0086$ & $86-0178$ & $86-0312$ \\
$85-55$ & $86-0093$ & $86-0197$ & $86-0320$ \\
$85-0009$ & $86-0094$ & $86-0199$ & $87-0015$ \\
$85-0023$ & $86-0101$ & $86-0208$ & $87-0018$ \\
$85-0024$ & $86-0105$ & $86-0209$ & $87-0018$ \\
$85-0027$ & $86-0121$ & $86-0220$ & $87-0022$ \\
$86-85$ & $86-0132$ & $86-0233$ & $87-0023$ \\
$86-149$ & $86-0136$ & $86-0234$ & \\
$86-0023$ & $86-0140$ & $86-0237$ & \\
$86-0029$ & $86-0141$ & $86-0250$ & \\
$86-0035$ & $86-0142$ & $86-0261$ & \\
$86-0047$ & $86-0146$ & $86-0272$ & \\
$86-0049$ & $86-0159$ & $86-0273$ & \\
$86-0068$ & $86-0163$ & $86-0278$ & \\
\hline
\end{tabular}

CPCF Sludge After Blending/Mixing

CNY 1 through 37

The Chem-Nuclear Systems, Inc. processing unit was unable to process the CPCF sludge, and only drum (CNY-6) was used.

All blended/mixed drums of CPCF sludge except CNY-6, which was processed during the demonstration, were returned to the vaults for storage. 


\section{C-4}

\section{ATTACHMENT 3}

Status Identification and Location of Residue Waste Streams from Y-12 Sludge Detoxification Demonstration

\begin{tabular}{||l|l|l|l|l||}
\hline Description and Origin & Container & Quantity & Identification & Location \\
\hline \hline $\begin{array}{l}\text { *Water with oils, grease, } \\
\text { and other organics (phase } \\
\text {-separator overflow) }\end{array}$ & 55 -gal drums & 12 & $\begin{array}{l}12782-1 \text { thru } \\
12782-12\end{array}$ & $\begin{array}{l}\text { Vault 4B or } \\
23\end{array}$ \\
\hline *Dry powder (kiln) & Tote bins & 2 & $\begin{array}{l}12783-1 \text { and } \\
12786-1\end{array}$ & $\begin{array}{l}\text { Vault 19 or } \\
23\end{array}$ \\
\hline $\begin{array}{l}\text { *Water with oils, grease, } \\
\text { other organics and } \\
\text { possibly some fine sludge } \\
\text { (heat exchanger flush) }\end{array}$ & 55 -gal drums & 5 & $\begin{array}{l}12784-1 \text { thru } \\
12784-5\end{array}$ & Vault 4B \\
\hline $\begin{array}{l}\text { *Water with oils, grease, } \\
\text { other organics and } \\
\text { possibly some fine sludge } \\
\text { (phase separator } \\
\text { blowdown) }\end{array}$ & 55 -gal drums & 7 & $\begin{array}{l}12785-1 \text { thru } \\
12785-7\end{array}$ & Vault 4B \\
\hline $\begin{array}{l}\text { *Water with oils, grease } \\
\text { and other organic } \\
\text { material (condensing } \\
\text { system) }\end{array}$ & 55 -gal drums & 24 & $\begin{array}{l}12781-1 \text { thru } \\
12781-24\end{array}$ & Vault 4B \\
\hline $\begin{array}{l}\text { Dry baleable waste } \\
\text { waste (personnel radcon } \\
\text { protection and cleanup } \\
\text { material) }\end{array}$ & 55 -gal drums & 23 & $10116-1$ thru \\
\hline $\begin{array}{l}\text { Dry baleable waste } \\
\text { (personnel radcon } \\
\text { protection and cleanup } \\
\text { material) }\end{array}$ & 55 -gal drums & 11 & Vault 4B \\
\hline *These waste streams have been characterized, and the data are available. & \\
\hline
\end{tabular}




$$
\begin{gathered}
\text { C-4 } \\
\text { D-1 } \\
\text { Appendix D }
\end{gathered}
$$

Report No. ER-90-002

\title{
Y-12 SLUDGE DETOXIFICATION DEMONSTRATION
}

\author{
FINAL REPORT
}

SUBMITTED TO

\begin{abstract}
MARTIN MARIETTA ENERGY SYSTEMS, INC. WASTE MANAGEMENT TECHNOLOGY CENTER CHEMICAL TECHNOLOGY DIVISION
\end{abstract}

Prepared by:

CHEM-NUCLEAR SYSTEMS, INC. SERVICES

140 Stoneridge Drive

Columbia, SC 29210
RUST FEDERAL

140 Stoneridge Drive

Columbia, SC 29210 
TABLE OF CONTENTS

EXECUTIVE SUMMARY $\ldots \ldots \ldots \ldots \ldots \ldots \ldots \ldots$

1.0 INTRODUCTION: OBJECTIVES AND SCHEDULE $\ldots \ldots \ldots \ldots \ldots$

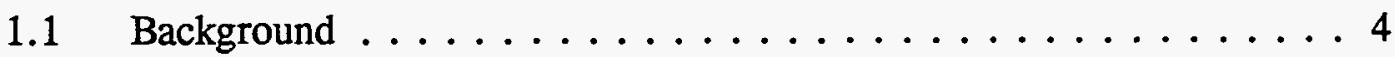

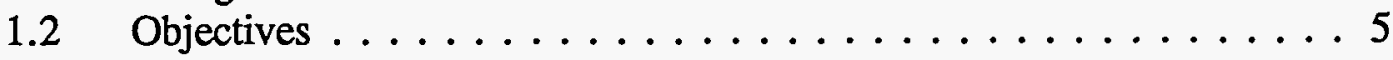

2.0 PROJECT DESCRIPTION $\ldots \ldots \ldots \ldots \ldots \ldots \ldots \ldots$

2.1 Process Overview . . . . . . . . . . . . 5

2.2 Description of Equipment $\ldots \ldots \ldots \ldots \ldots \ldots \ldots$

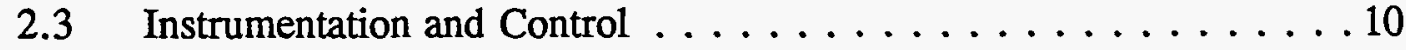

3.0 TEST OPERATIONS AND EMISSIONS $\ldots \ldots \ldots \ldots \ldots \ldots$

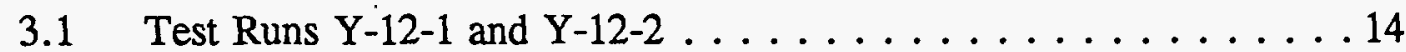

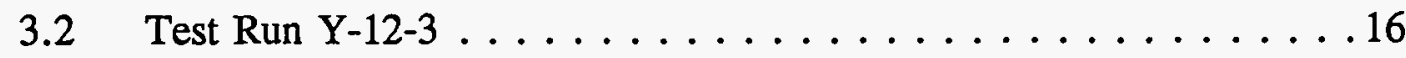

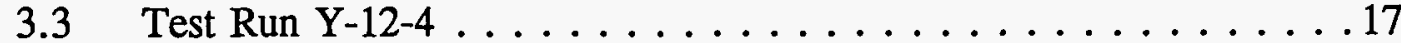

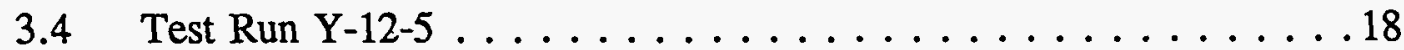

3.5 . Test Run $\mathrm{Y}-12-6 \ldots \ldots \ldots \ldots \ldots \ldots \ldots$

4.0 DESCRIPTION OF PROBLEMS $\ldots \ldots \ldots \ldots \ldots$

5.0 SUMMARY OF ANALYTICAL RESULTS $\ldots \ldots \ldots \ldots \ldots 21$

5.1 Waste Characterization . . . . . . . . . . . . 21

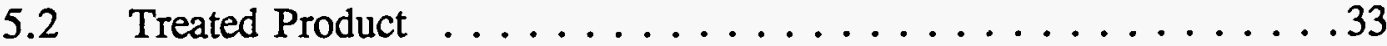

5.3 Residuals . . . . . . . . . . . . . . . 34

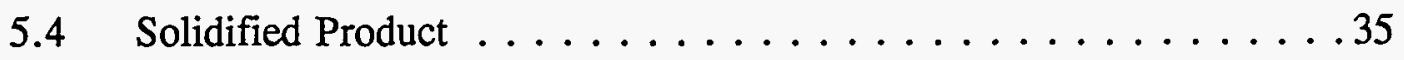

6.0 DISCUSSION OF PROCESS EMISSIONS AND.

VOLUMETRIC RESIDUE CHANGES . . . . . . . . . . 37

7.0 DECONTAMINATION RESULTS $\ldots \ldots \ldots \ldots \ldots \ldots \ldots$

8.0 COST ISSUES $\ldots \ldots \ldots \ldots \ldots \ldots \ldots \ldots \ldots \ldots \ldots \ldots \ldots \ldots \ldots$

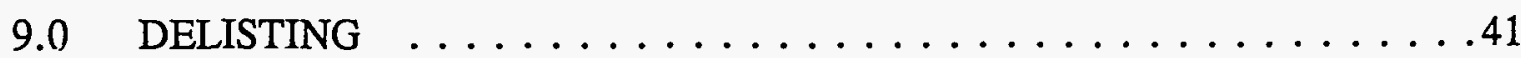


C-4

TABLES

1 COMPARISON OF Y-12 SLUDGES WITH X*TRAX ${ }^{\mathrm{TM}}$ DESIGN BASIS 6

2 FEED MATERIAL PARAMETERS $\ldots \ldots \ldots \ldots \ldots \ldots \ldots$

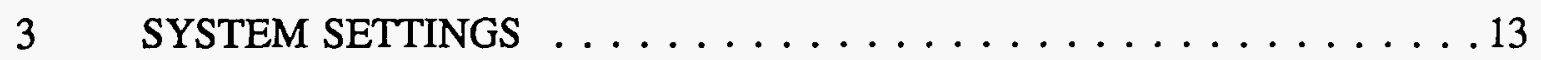

4 PROCESS VENT-ORGANICS RELEASED $\ldots \ldots \ldots \ldots \ldots \ldots$

5 SUMMARY OF ANALYTICAL RESULTS, K-1232 WASTE . . . . . 23

6 SUMMARY OF ANALYTICAL RESULTS, CPCF SLUDGE . . . . 28

$7 \quad$ Y-12 SLUDGE ANALYSIS SUMMARY $\ldots \ldots \ldots \ldots \ldots$

8 TREATED PRODUCT-KEY ANALYTICAL RESULTS $\ldots \ldots \ldots \ldots 34$

9 RESIDUALS ANALYSES SUMMARY $\ldots \ldots \ldots \ldots \ldots$

10 LEACH TEST RESULTS FOR SOLIDIFIED K-1232 PRODUCT . . . . . 36

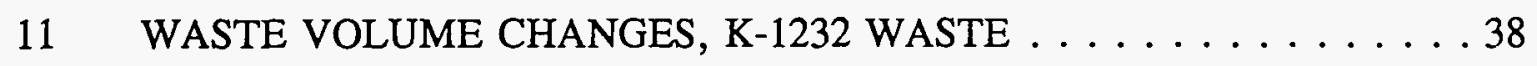

12 K-1232, TREATMENT/DISPOSAL COST ESTIMATE SUMMARY . . . 40

\section{FIGURES}

1 PROCESS FLOW DIAGRAM $\ldots \ldots \ldots \ldots \ldots \ldots$ 
Martin Marietta Energy Systems

Y-12 Sludge Detoxification Demonstration Final Report

\section{EXECUTIVE SUMMARY}

The Y-12 Sludge Detoxification Demonstration Project was performed by Chem-Nuclear Systems, Inc. (CNSI) during October 1988 at the Oak Ridge Gaseous Diffusion Plant (ORGDP) in Tennessee. Both the ORGDP and the Y-12 plant are operated by Martin Marietta Energy Systems, Inc. (Energy Systems) for the U.S. Department of Energy (DOE).

The project objective was to demonstrate the capability of a two-step process that would produce RCRA delistable waste forms from two Y-12 mixed waste sludges. The first step utilized the Chemical Waste Management, Inc. (CWM) $X^{*} \operatorname{TRAX}^{\mathrm{TM}}$ process to remove the bulk of the organic material and moisture from the sludges. The $\mathrm{X}^{*} \mathrm{TRAX} \mathrm{X}^{\mathrm{TM}}$ system, now available through CWM affiliate RUST Federal Services, is a thermal desorption system capable of removing volatile chemicals and metals from soils and sludges without releasing the contaminants to the environment. The second step involved stabilizing samples of the treated sludge product using a CNSI- proprietary solidification process. A Process Flow Diagram is shown in Figure 1 which depicts the flow of materials through the process. Due to project schedule and cost constraints, the stabilization was performed in laboratory scale equipment instead of full-scale equipment. The stabilized final product was made available to Energy Systems for evaluation for delisting and disposal as a low level radioactive waste in an existing permitted facility.

Safety and environmental compliance were of prime importance during conduct of this project. During the demonstration, no detectable radioactivity was discharged to the environment through the process vent. All liquids condensed in the process were managed on-site by Energy Systems in existing permitted mixed waste treatment facilities.

This demonstration showed that one of the sludges, the $\mathrm{K}-1232$ sludge, could be successfully processed by the $\mathrm{X}^{*} \mathrm{TRAX} \mathrm{X}^{\mathrm{TM}}$ system at feed rates $30 \%$ above anticipated feed rates. Samples of the solidified final product satisfactorily passed both Extraction Procedure-Toxicity (EP-Tox) and Toxicity Characteristics Leaching Procedure (TCLP) tests and would be strong candidates for delisting. The second waste, CPCF sludge, could not be processed due to its unusually high organic content which caused plugging of the $\mathrm{X}^{*} \mathrm{TRAX} \mathrm{X}^{\mathrm{TM}}$ gas handling system. This sludge is not a strong candidate for delisting without further modification to the $\mathrm{X}^{*} \mathrm{TRAX}^{\mathrm{TM}}$ unit.

The following statements summarize experiences with the Y-12 Sludge Detoxification demonstration program: 
- The Y-12 Sludge Detoxification Demonstration Project was successfully completed in a safe, efficient manner.

- Air emissions for both Volatile Organic Compounds (VOCs) and radioactivity were below all applicable standards.

- The necessary state permit was successfully obtained for operating the pilot system. Although EPA Region IX did not require a RCRA RD\&D permit, the $\mathrm{X}^{*} \mathrm{TRAX}^{\mathrm{TM}}$ Unit was operated under a modification to the DOE RCRA Part A interim status permit.

- The unit operated successfully within the permit limits and conditions of both the state permit and the DOE RCRA Part A interim status permit.

- The CWM X*TRAX ${ }^{\mathrm{TM}}$ system operated with minimal down time. Any mechanical problems encountered were resolved effectively and quickly.

- Radioactivity levels in the condensed water were sufficiently below EPA drinking water standards ( 40 CFR Part 141) that the water could be processed by the onsite waste water treatment plant.

- The CPCF sludge could not be processed using the installed off-gas handling unit due to the formation of solid organics in the off-gas condensers. This condition, peculiar to this waste, caused plugging and loss of recycle gas flow. Modification of the condenser system's first and second stages should eliminate this problem, with successful treatment and stabilization to meet delisting criteria likely.

- The K-1232 sludge was successfully processed at $30 \%$ above design feed rate. Representative samples of the processed sludge were solidified and passed both the EP-Toxicity test and the Toxic Characteristic Leaching Procedure (TCLP). After processing using the $X^{*} T_{R A X}{ }^{T M}$ system offered by RUST Federal Services and solidification using CNSI's proprietary formulations, the K-1232 sludge would be a candidate for delisting. 


\subsection{INTRODUCTION}

\section{$1.1 \quad$ Background}

This report has been prepared to describe the Y-12 Sludge Detoxification Demonstration project performed by Chem-Nuclear Systems, Inc. (CNSI) and Chemical Waste Management, Inc. (CWM). In order to provide a comprehensive discussion of the project, the following topics have been included:

- Project Objectives - Lists the major objectives addressed by the project.

- Project Description - Provides information on the process employed, the project schedule, and equipment employed.

- Test Operations and Emissions - Describes the conduct of operations and results obtained.

- Description of Problems - Describes problems encountered and corrective actions taken.

- Summary of Analytical Results - Provides analytical results for the waste characterization, sludge feed, related product, residuals, and solidified product.

- Process Emissions and Volumetric Residue Changes - Provides an assessment of emissions to the environment based on data from process monitoring equipment, vent gas sample analyses, and the radiological monitoring program.

- Decontamination Results - Describes equipment release limits, decontamination efforts, and results.

- Cost Issues - States cost estimate assumptions and shows the derivation of a per-drum cost.

- Delisting - Explains considerations for delisting and conclusions regarding solidification formulations selected. 


\section{$1.2 \quad$ Objectives}

The major goals for the $\mathrm{X}^{*} \mathrm{TRAX}{ }^{\mathrm{TM}} \mathrm{Y}-12$ Sludge Detoxification Demonstration Project were to:

- Demonstrate an innovative technology.

- Determine if the $X^{*} T R A X^{\mathrm{TM}}$ process could produce a stabilized solid from two different Y-12 plant mixed waste sludges that would meet RCRA delisting criteria, thus permitting their management as a low level radioactive waste.

- Analyze the economics of the treatment process.

- Perform a successful decontamination of the system, measured by Energy Systems disposal site and release criteria, while minimizing the generation of secondary waste (contaminated equipment, filters etc).

\subsection{PROJECT DESCRIPTION}

\subsection{Process Overview}

CNSI and CWM employed a two-step process, starting with the $X^{*} T_{R A X}{ }^{\mathrm{TM}}$ process as a pretreatment, followed by CNSI's commercial cement solidification process. The purpose of $X^{*} T_{R A X}{ }^{\mathrm{TM}}$ was to remove, through thermal desorption, enough of the organic constituents to then allow CNSI to immobilize the metals using solidification.

The concept of using the $\mathrm{X} * \mathrm{TRAX}{ }^{\mathrm{TM}}$ thermal treatment process was demonstrated in bench scale tests at a CWM laboratory. However, since the waste analyses performed by Energy Systems were not available until the project was well under way, conservative, vice optimized, operating parameters had to be established to ensure contaminant levels were as low as achievable within the capabilities of the equipment.

The Y-12 wastewater treatment sludges are F-006 listed hazardous wastes which also contain radioactive depleted uranium, classifying them as a mixed waste. There were two types of $\mathrm{Y}-12$ sludges:

1. K-1232, a Central Pollution Control Facility (CPCF) sludge that was dewatered with a centrifuge and then allowed to gravity settle. 
2. CPCF sludge, another Central Pollution Control Facility (CPCF) sludge which was untreated and had the consistency of filter cake.

Table 1 compares some of the characteristics of the sludges with the design basis for the $X^{*} T_{R A X}{ }^{\mathrm{TM}}$ system. The low solids content of both of these sludges and high organic content of the CPCF sludge presented a significant challenge to the $\mathrm{X}^{*} \mathrm{TRAX}^{\mathrm{TM}}$ system. Specifically, the CPCF sludge exceeded the $\mathrm{X} * \mathrm{TRAX}^{\mathrm{TM}}$ organic contaminant design basis and both sludges exhibited substantially lower solids content than the $\mathrm{X}^{*} \mathrm{TRAX}^{\mathrm{TM}}$ design basis.

TABLE 1

Comparison of Y-12 Sludges with $X{ }^{*}$ TRAX $^{\mathrm{TM}}$ Design Basis

$\underline{\text { LIMIT }} \underline{\text { PREFERRED }} \underline{\mathrm{K}-1232}$

CPCF

$\begin{array}{llll}\text { Total Solids (\%) } & \text { Min }=40 & >60 & 29\end{array}$

40.3

Total Organics $(\%) \quad \operatorname{Max}=10 \quad<5 \quad>11$

$>7$

$\mathrm{pH}$

4-11

12.8

27

The project plan involved processing 24 drums each of the $\mathrm{K}-1232$ and $\mathrm{CPCF}$ sludges. Initially, three to six drums of each sludge were to be processed to optimize $X^{*} \mathrm{TRAX}{ }^{\mathrm{TM}}$ operating conditions. Finally, the remaining drums were to be processed and the treated solids collected for solidification by CNSI. Data were collected for mass and energy balances and also for economic evaluation of the process.

The EPA Region IV determined that a RCRA RD\&D permit was not required for the demonstration. A RCRA part A permit modification and a state air permit were then successfully obtained. Finally, DOE approval was granted to perform the on-site demonstration. 
The project schedule for the $\mathrm{X}^{*} \mathrm{TRAX}^{\mathrm{TM}}$ demonstration was as follows:

\begin{tabular}{||l|l||}
\hline \multicolumn{1}{|c|}{ Task } & \multicolumn{1}{|c||}{ Dates Accomplished } \\
\hline \hline Equipment setup and checkout & $08 / 15 / 88$ to $09 / 02 / 88$ \\
\hline K-1232 sludge parameter setting & $10 / 03 / 88$ to $10 / 08 / 88$ \\
\hline CPCF sludge parameter setting & $10 / 10 / 88$ \\
\hline K-1232 sludge treatment & $10 / 17 / 88$ to $10 / 22 / 88$ \\
\hline CPCF sludge treatment & No treatment tests \\
\hline Decontaminate equipment & $10 / 24 / 88$ to $11 / 11 / 88$ \\
\hline Demobilization & $11 / 14 / 88$ \\
\hline $\begin{array}{l}\text { Immobilization and leachability tests of the } \\
\text { dried product }\end{array}$ & $08 / 89$ \\
\hline
\end{tabular}

Prior to initiating the demonstration, a number of tasks, plans, procedures, and studies were developed and conducted. Energy Systems took the lead by preparing a plan to select the demonstration drums from a larger population, blending those drums and characterizing the waste. CNSI/CWM wrote a Detailed Implementation Plan (DIP) describing how the project would be run, an Environmental Health and Safety Plan, Quality Assurance Plan, and an $\mathrm{X}^{*} \mathrm{TRAX}^{\mathrm{TM}}$ Sampling and Analysis Plan, as well as operating procedures for the $\mathrm{X}^{*} \mathrm{TRAX}^{\mathrm{TM}}$ unit, solidification systems, and peripheral operating equipment.

A risk assessment entitled, "Qualitative Risk Assessment of the $\mathrm{X}^{*} \mathrm{TRAX} \mathrm{X}^{\mathrm{TM}}$ Thermal Separator System," was conducted by Battelle, Columbus Division, and a safety analysis was performed by Energy Systems. Subsequently, a more comprehensive safety study for the project was completed by Impell under contract to Energy Systems. As part of the safety study, an analysis of the vent stack gas emissions was completed which resulted in a redesign of the $\mathrm{X}^{*} \mathrm{TRAX} \mathrm{X}^{\mathrm{TM}}$ vent stack which required relocating it remotely from the $\mathrm{X}^{*} \mathrm{TRAX}^{\mathrm{TM}}$ unit, and incorporating an additional blower.

Several other $\mathrm{X} * \mathrm{TRAX}{ }^{\mathrm{TM}}$ system design modifications were also identified prior to the demonstration, partly to account for unusual/unexpected sludge conditions, such as the following: 
- The sludge was inspected by CWM and found to be of much thicker consistency than anticipated. Tests were conducted at Energy Systems to support a modified method of feeding the sludge into the dryer. It was found that the drummed material, which had previously been blended, separated during storage. Inspection of the drums revealed water on the top and thick sludge material on the bottom. The original drum feed system involved movement of the drums with a forklift and dumping the sludge into a feed pump hopper. The thicker than expected consistency caused CNSI/CWM to modify the feed method to include dumping the drums onto a specially designed table and removing the sludge from the drums with a "garden hoe." The drum residuals were then washed into the pump hopper.

- Because of the sludge consistency, the dryer unit feed system was redesigned from a belt conveyer to a pump system prior to mobilization on the K-25 site. This change required extensive last minute design modifications.

- The discharge system was redesigned after discussions with Energy Systems Health and Safety personnel. The modified design provided complete containment for the dried product from the dryer discharge to the storage bins.

- A number of minor safety modifications were made to the dryer and gas handling trailer after a safety inspection by Energy Systems.

\subsection{Description of Equipment}

The mobile Pilot $\mathrm{X}^{*} \mathrm{TRAX}{ }^{\mathrm{TM}}$ system consists of two trailers, one containing the thermal separator unit (dryer) and one containing the off-gas handling system. In the $\mathrm{X}^{*} \mathrm{TRAX} \mathrm{X}^{\mathrm{TM}}$ process, contaminated soils or sludges are fed into the dryer which is an indirect fired rotary kiln. Within the dryer, the feed material is heated to $500^{\circ}-800^{\circ} \mathrm{F}$ in order to volatilize the moisture and the organic contaminants. An inert nitrogen carrier gas is recirculated through the dryer to transport the volatilized water and organics to the off gas handling system where they are condensed and collected for further treatment. Because the dryer is indirectly fired, the products of combustion do not mix with either the waste or the volatilized organics. This dramatically reduces the size and complexity of the off gas handling system. Furthermore, the relatively low processing temperature and the use of inert carrier gas prevent undesirable chemical reactions of the organic contaminants. 
The sludge feed material was delivered to the dryer by a Moyno ${ }^{\mathrm{TM}}$ progressive cavity sludge pump. The pump was connected by hose to a sludge feed lance that penetrated through the dryer's feed breech and dropped material into the dryer's rotating cylinder. Drums of sludge were tipped into the sludge pump's hopper using a hydraulic drum tipper.

The hot, treated solids exit from the dryer's product breech and fall into a product screw conveyor that transfers the material to a rotary air lock valve. Normally, the solids would discharge directly from the rotary valve into product containers. For this demonstration, in order to maintain complete containment of the radioactive dust from the product, a supplemental product conveyer was added to transfer material to large enclosed bins. The bins were equipped with HEPA filters to remove the displaced air. The existing product screw was traced with refrigeration tubing to reduce the temperature of the product prior to discharging the solids into the supplemental conveyer and bin. A sample port was installed on the inlet hopper of the transfer conveyor to allow for periodic sampling of the treated product.

The carrier gas containing the volatilized materials is treated in a three stage cooling and condensing train to remove the organic materials. The carrier gas exits the dryer at $400^{\circ}-600^{\circ} \mathrm{F}$ and enters the spray tower where it undergoes an adiabatic cooling operation and is cooled to approximately $170^{\circ} \mathrm{F}$. Here, essentially all of the particulate carry-over is removed along with the high volatility organics.

The water saturated carrier gas exits the spray tower and is further cooled to $80^{\circ}$ $120^{\circ} \mathrm{F}$ in a shell and tube heat exchanger. Here, a large portion of the water vapor is condensed, along with the organic components of intermediate and low volatility.

The carrier gas is then further cooled to less that $40^{\circ} \mathrm{F}$ in a second shell-and-tube refrigerated heat exchanger. This condenses essentially all of the remaining organics and most of the remaining water vapor.

The carrier gas is then reheated with an electric induction heater to raise the temperature above the dew point prior to reaching the blower suction. The blower transfers the carrier gas through a propane fired heater where it is reheated and returned to the dryer. The carrier gas flow rate is approximately $100 \mathrm{scfm}$.

The only gaseous release points for the process are: 
1. A low flow vent stream which is discharged to the atmosphere after passing through a 3 micron filter and a carbon adsorption drum.

2. Breathing losses from the collection tanks.

The vent stream is operated at $1-10 \mathrm{scfm}$. Its purpose is to maintain low oxygen concentration in the carrier gas. These vented gases include primarily nitrogen, water and oxygen, along with a small amount of organics.

Water and organics that are condensed in the spray tower are separated in an inclined plate oil/water separator. The water phase is recirculated back to the spray tower. Condensed organics from the two heat exchangers are collected on the top of the condensate tanks. Surplus water that is generated by the system may require subsequent treatment external to the gas handling trailer. In a fullscale system, this water, if low in organics, could be used for solidification of the dried product. Provision for treatment of the water was not part of the system demonstration.

The organic liquids that are produced similarly require treatment external to this system. A provision was included to blow down accumulated sludges from both the plate separator and the storage tanks. Treatment of sludge was either by reprocessing as feed to the dryer or by an alternative process external to the system, depending on the composition of the sludge.

\section{$2.3 \quad$ Instrumentation and Control}

Control of the $\mathrm{X}^{*} \mathrm{TRAX}^{\mathrm{TM}}$ pilot unit is accomplished with a combination of automatic, remote manual, and manual controls. Each trailer has a control panel to house panel- mounted indicators and controls. The burner controls for both the indirect fired dryer and the carrier gas reheater were provided by the manufacturers and utilize standard combustion control technology. Carrier gas recirculation rate and dryer internal pressure are controlled using modulating valves. The balance of the process parameters, such as coolant flow rates and intermediate temperatures, are manually controlled. Temperature, pressure, and flow indicators are provided so that the manual control valves can be set appropriately. The discharge end of the dryer is maintained at a slight vacuum to preclude leakage out of the system. This is done by adjusting the vent flow rate to ensure suction at the dryer from the recirculation blower. The recirculation flow to the dryer is controlled by an automatic controller. High and low pressure in the dryer are annunciated to alert the operator of upset conditions. 
Oxygen concentration in the system is maintained below the combustibility limit ( $7 \%$ by volume) by the continuous $1-10 \%$ vent stream. Nitrogen is added to the system to balance this vent flow. The oxygen concentration is monitored continuously with an in-line analyzer. This analyzer has two alarm outputs, a high alarm and a high-high alarm. The high alarm is set at $4 \%$ and the high-high at $7 \%$. If oxygen concentration rises above the high alarm setpoint, a supplemental $5-10 \mathrm{cfm}$ nitrogen stream is automatically introduced to the dryer discharge breech to help reduce the oxygen level. Also, an alarm for high oxygen concentration annunciates to signal the operator. If the supplemental nitrogen and operator attention fail to control the oxygen ingress and oxygen concentration continues to increase above the high-high oxygen concentration alarm, the panel will annunciate to signal required shutdown. Simultaneously, an additional high flow nitrogen stream is introduced to the dryer breech at $30 \mathrm{cfm}$. This is in addition to the supplemental and makeup nitrogen already being introduced to the system. This will blanket the system and allow orderly shutdown. The dryer feed pump also shuts down on high-high oxygen.

An in-line organic vapor analyzer is installed in the vent piping to provide continuous monitoring of atmospheric emissions. This instrument provides an indication of breakthrough on the vent's carbon adsorption unit. This data allows evaluation of the efficiency of the first carbon drum. A second carbon drum is installed in series as added precaution in the event of an unexpected breakthrough of the first carbon drum.

\subsection{TEST OPERATIONS AND EMISSIONS}

All twenty-four drums of the K-1232 sludge, totalling 10,700 pounds were successfully processed with the $\mathrm{X}^{*} \mathrm{TRAX} \mathrm{X}^{\mathrm{TM}}$ system according to the project plan. The average feed rate during the K-1232 production run was 240 pounds/hour. The pilot system's design feed capacity is 420 pounds/hour at $30 \%$ moisture, which equates to 126 pounds/hour of water. Water evaporation is a rate-limiting parameter for the $\mathrm{X}^{*} \mathrm{TRAX}{ }^{\mathrm{TM}}$ process. With the $\mathrm{K}-1232$ sludge's $70 \%$ moisture, 168 pounds/hour of water were fed, which is $30 \%$ higher than the design value. The gross heat input was 1.1 million Btu/hour, also well above the design value.

The treated product that resulted from the $\mathrm{K}-1232$ sludge was a powdery, free flowing material with some small granules present. It was gray in color.

The condensate that was produced had no distinguishable free organic layer. It was a relatively clear continuous aqueous phase, that had a slight yellowish color and no appreciable visible suspended solids. Toward the end of each of the two 
production runs, a thin layer of floating organic liquids was observed in the condensate collection tanks. This organic liquid had evidently been accumulating throughout the run and only became visible near the end of the test after many gallons of condensate had been collected and transferred out of the tanks from the bottom.

Each of the test runs, including the initial demonstrations using the clay surrogate, were identified with a unique run I.D. number. These were serial numbers of the general form: $\mathrm{Y}-12-\mathrm{X}$, where $\mathrm{X}$ identified a run number from 1 to 6 .

The operating information from each of these test runs is summarized in Tables 2 and 3. This information includes both equipment set points and the measured results, such as feed rates and product temperatures.

TABLE 2

FEED MATERIALS PARAMETERS

Pilot $X^{\star}$ TRAX ${ }^{\mathrm{TM}}: Y-12$ Sludge Detoxification Demonstration

\begin{tabular}{|c|c|c|c|c|c|c|c|c|c|}
\hline Run & & Feed & $\begin{array}{l}\text { Total } \\
\text { Feed }\end{array}$ & $\begin{array}{l}\text { Feed } \\
\text { Time }\end{array}$ & $\begin{array}{l}\text { Avg Feed } \\
\text { Rate }\end{array}$ & $\begin{array}{l}\text { Feed } \\
\text { Sol ids }\end{array}$ & $\begin{array}{l}\text { Feed } \\
\text { O\&G }\end{array}$ & Solids & $\begin{array}{l}\text { Feed Rate } \\
\text { Hater }\end{array}$ \\
\hline $\mathrm{lb} / \mathrm{hr}{ }^{\text {No. }}$ & Date & Mat. & lb & $h r$ & $\mathrm{lb} / \mathrm{hr}$ & $\%$ & ppm & lb/hr & lb/hr \\
\hline
\end{tabular}

\begin{tabular}{|c|c|c|c|c|c|c|c|c|c|c|}
\hline - - & $Y-12-1$ & $8 / 30 / 88$ & CLAY SURROGATE & 1,070 & 2.43 & 440 & 70 & $\cdots$ & 308.3 & 132.1 \\
\hline$\ldots$ & $Y-12-2$ & $9 / 01 / 88$ & CLAY SURROGATE & 1,581 & 4.50 & 351 & 70 & -- & 245.1 & 105.4 \\
\hline 1.67 & $Y-12-3 A$ & $10 / 07 / 88$ & K-1232 PARAM. SET & 817 & 3.42 & 239 & 29 & 7,000 & 69.3 & 168.0 \\
\hline 1.67 & $Y-12-3 B$ & $10 / 07 / 88$ & K-1232 PARAM. SET & 717 & 3.00 & 239 & 29 & 7,000 & 69.3 & 168.0 \\
\hline 2.24 & $Y-12-3 C$ & $10 / 07 / 88$ & K-1232 PARAM. SET & 719 & 2.25 & 319 & 29 & 7,000 & 92.5 & 224.6 \\
\hline 2.24 & $Y-12-3 D$ & $10 / 07 / 88$ & K-1232 PARAM. SET & 680 & 2.13 & 319 & 29 & 7,000 & 92.5 & 224.6 \\
\hline 21.00 & $0^{y-12-4}$ & $10 / 10 / 88$ & CPCF PARAM. SET & 517 & 2.50 & 207 & 40 & 101,556 & 82.8 & 102.5 \\
\hline 1.58 & $Y-12-5$ & $10 / 19 / 88$ & K-1232 PROOUCTION & 4,796 & 21.30 & 225 & 29 & 7,000 & 62.0 & 158.3 \\
\hline 1.85 & $Y-12-6$ & $10 / 22 / 88$ & K-1232 PRODUCTION & 2,953 & 11.17 & 264 & 29 & 7,000 & 76.6 & 185.9 \\
\hline
\end{tabular}


Martin Marietta Energy Systems

Y-12 Sludge Detoxification Demonstration Final Report

Note: Run $Y-12-3$ broken down into sub-runs $A-D$ for different dryer settings. 


\section{TABLE 3}

\section{SYSTEM SETTINGS}

Pilot $\mathrm{X} * \mathrm{TRAX} \mathrm{X}^{\mathrm{TM}}$ : $\mathrm{Y}-12$ sludge Detoxification Demonstration

\begin{tabular}{|c|c|c|c|c|c|c|c|c|c|c|c|c|c|}
\hline & & Cyl & Feed & Feed & Barre & $\mathrm{Calc}{ }^{\prime} \mathrm{c}$ & $\mathrm{Fi}$ & & & Temp & eratures & (F) & \\
\hline Run & & Spd & Pump & Rate & slope & Res Time & Vol. & Zone & Zone & Zone & Gas & Product & Propane \\
\hline No. & Date & RPM & RPM & $1 b / h r$ & In/Ft & Min. & 8 & 1 & 2 & 3 & Out & $\mathrm{TC}-11$ & MMBtu / \\
\hline
\end{tabular}

$\begin{array}{lrrrrrrrrrrrrrr}\mathrm{Y}-12-1 & 8 / 30 / 88 & 1.7 & 10.8 & 440 & 3 / 16 & 123 & 1.5 & 825 & 825 & 800 & 490 & 450 & 650 & 1.14 \\ \mathrm{Y}-12-2 & 9 / 01 / 88 & 1.7 & 9.4 & 351 & 3 / 16 & 123 & 1.2 & 800 & 775 & 800 & 490 & 460 & 670 & 0.77 \\ \mathrm{Y}-12-3 \mathrm{~A} & 10 / 07 / 88 & 1.6 & 8.9 & 239 & 3 / 16 & 130 & 3.0 & 750 & 700 & 675 & 500 & 340 & 340 & 0.78 \\ \mathrm{Y}-12-3 \mathrm{~B} & 10 / 07 / 88 & 1.6 & 8.9 & 239 & 3 / 16 & 130 & 3.0 & 775 & 750 & 750 & 500 & 370 & 480 & 0.89 \\ \mathrm{Y}-12-3 \mathrm{C} & 10 / 07 / 88 & 1.6 & 11.8 & 319 & 3 / 16 & 130 & 4.0 & 800 & 775 & 775 & 505 & 360 & 385 & 0.94 \\ \mathrm{Y}-12-3 \mathrm{D} & 10 / 07 / 88 & 1.6 & 11.8 & 319 & 3 / 16 & 130 & 4.0 & 850 & 850 & 825 & 505 & 400 & 480 & 1.18 \\ \mathrm{Y}-12-4 & 10 / 10 / 88 & 1.6 & 8.0 & 207 & 3 / 16 & 130 & 2.1 & 750 & 725 & 700 & 490 & 400 & 575 & 0.77 \\ \mathrm{Y}-12-5 & 10 / 19 / 88 & 1.2 & 10.4 & 225 & 3 / 16 & 169 & 3.7 & 820 & 830 & 830 & 485 & 440 & 630 & 1.08 \\ \mathrm{Y}-12-6 & 10 / 22 / 88 & 1.2 & 10.6 & 264 & 3 / 16 & 169 & 4.3 & 825 & 845 & 860 & 480 & 440 & 660 & 1.11\end{array}$


The process vent was continuously monitored for total organics using a Horiba FIA flame ionization analyzer. This analyzer measures the total carbon in the vent gas and gives a value of total organics which is calibrated against a methane standard. Consequently, the results are reported as "xxx ppm total organics as methane." Table 4 is a summary of the data collected with this instrument for each of the test runs, as well as an estimate of the total organic emission. Throughout the test, the organic emission rate was consistently at least a factor of 10 below the permit limits. As can be seen in Table 4, the organic emission rate was very low throughout the tests.

Release

Run ID Avg Vent Conc.

TABLE 4

PROCESS VENT - ORGANICS RELEASED

\section{$-$}

$\mathrm{Y}-12-3$

$\mathrm{Y}-12-5$

$Y-12-6$

169

283

(ppm methane)

203
Avg Vent Rate

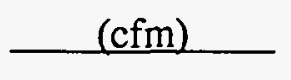

6.2

6.1

6.2

5.7
Avg Release

Tota 1

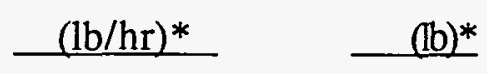

0.0027

006

0,00

0.40

0.019

0.15

* Assumes average organic molecular weight of 75.

\subsection{Test Runs $\mathrm{Y}-12-1$ and $\mathrm{Y}-12-2$}

Prior to the processing of either of the mixed waste sludges through $X^{*} \mathrm{TRAX}^{\mathrm{TM}}$, testing was performed using a simulated sludge to verify proper equipment operation and to provide a check of the waste handling procedures and contamination control measures.

A surrogate sludge was prepared using playbox sand, AP Green refractory clay (-28 mesh) and Moltan Safety Absorbent, a clay-based absorbent material.

These materials were blended in $2: 4: 3$ proportions, to which water was added to produce a $30 \%$ moisture content sludge. This made a paste that resembled "chip dip" which was very pumpable using the Moyno ${ }^{\mathrm{TM}}$ pump, but was not runny. 
Martin Marietta Energy Systems

Y-12 Sludge Detoxification Demonstration Final Report

The sludge would readily take the shape of a beaker, but did not run out when the beaker was turned on its side.

During the first clay surrogate test run, Y-12-1, the system performed as expected. The system had a dust leak at the sample port for the product transfer conveyor that was eliminated by placing the sample port inside of a radiological glove bag. The high temperature gas reheater also experienced several flame out conditions, which were corrected by removing a $90^{\circ}$ elbow at its stack discharge and replacing it with a "chinese hat." Also, additional splash protection was constructed around the feed hopper to control contamination release.

Because the first test duration was about 2.5 hours, it did not thoroughly test the product handling system's capability to tolerate high temperature product as it was still heating up when feed was terminated.

Therefore, a second longer duration test run was performed to check out the product handling system and evaluate the improved contamination control measures of the feed hopper and the product sample port. The system was fed for 4.5 hours for this test. The product material temperature discharge from the refrigerated product screw levelled off slightly above $300^{\circ} \mathrm{F}$. The product handling system tolerated this temperature well, confirming its ability to perform during actual waste processing. Also, the contamination control measures performed as desired, leaving high confidence that the demonstration could meet the "zero release" objective.

During this second surrogate test, two additional problems were observed that required minor modifications to the equipment. First, the sludge feed lance at the entrance to the hot section plugged during start up, which required that a $45^{\circ}$ elbow be removed to allow free passage of the sludge. Second, the dryer's product thermocouple assembly was being hit by the mechanical lump crusher that was installed inside the dryer cylinder. This lump crusher was fabricated especially for the Y-12 demonstration to size reduce balls of sludge that tend to form inside of the rotating dryer cylinder.

To eliminate this interference, about six inches was cut from the end of the lump crusher, and the material retaining dam inside the dryer was removed from the end of the cylinder and a new larger dam fabricated and welded into the dryer. The above modifications were completed by Energy Systems personnel.

The equipment was then fully checked out and ready for the processing of the mixed waste sludges. 
Martin Marietta Energy Systems

Y-12 Sludge Detoxification Demonstration Final Report 
Martin Marietta Energy Systems

Y-12 Sludge Detoxification Demonstration Final Report

\subsection{Test Run Y-12-3}

Three separate attempts were made on different days to initiate equipment start up for the K-1232 sludge parameter setting test run, Run Y-12-3. The first attempt was aborted when the sludge could not be removed from the drums by tipping them and using hand tools to scrape the sludge. The sludge had consolidated into a stiff mass during the six month storage period after blending. The drums were then returned to Energy Systems operations, where they were reblended (using a mixer) into a flowable sludge that could be removed from the drums. No additional water was added to the waste during this mixing operation. This property of decreased viscosity as a result of mixing classifies the K-1232 sludge as thixotropic.

The second Y-12-3 start-up was aborted when the dryer cylinder drive failed. This failure is described later in Section 4.0.

The third Y-12-3 start- up proceeded smoothly and feed was introduced to the $\mathrm{X}^{*} \mathrm{TRAX}^{\mathrm{TM}}$ dryer at approximately noon on October 7, 1988. Four separate operating conditions were investigated during this test run, which lasted for a total of 10.8 hours. Two feed rates and four different furnace settings were used to evaluate system performance on the K-1232 sludge.

During this test run, the product temperature was below the target value of 600 $650^{\circ} \mathrm{F}$ for each of the four conditions. This data was then used to determine dryer operating conditions for the K-1232 production run(s) that did achieve the product temperature goal. The balance of the equipment performed as expected, namely the scrubber satisfactorily removed both particulate solids and high boiling organics from the carrier gas, and the condensers produced a relatively clean condensed water phase. A small quantity of an oily froth was skimmed from the scrubber's phase separator. This froth was placed back into the sludge feed hopper with the untreated waste.

Also during the test run, the performance of the gas treatment system was somewhat different than that experienced when treating soils. This was a result of the high moisture content of the feed. The condensation of this water caused oscillating pressure swings of larger magnitude than normally observed for soils. An increase of the carrier gas recirculation rate from 75 to $85 \mathrm{cfm}$ during the run dampened the oscillations and made the gas system easier to control.

After completion of feeding the K-1232 sludge, a portion of a drum of the clay surrogate sludge amounting to 114 pounds was added to the feed hopper to "chase" the waste from the system and remove gross residual contamination. 
During the test run, stack samples were taken from both the process vent line and the water collection tank vent lines. These sampling trains were set up to monitor for organic, particulate and radioactive emissions. The analysis of these samples showed both volatile organics and particulate emissions to be non-detectable. Uranium was detected in the process vent at 16.5 micrograms per cubic meter, which was a factor of about two above the historical background level for the $\mathrm{K}$ 25 site.

Carbon monoxide was monitored in the process vent and ranged from 300 to 600 ppm, which was 100 times less than preliminary calculations had estimated it might be. This low CO level was well below concern. Since there was still a very small quantity of radioactivity it was decided that a HEPA filter would be added to the process vent and that testing would continue.

\subsection{Test Run Y-12-4}

Test run Y-12-4 was the parameter setting run for the CPCF sludge. This run was aborted at 2.5 hours after feeding a little over one drum of material because of the buildup of crystalline organic material which plugged the gas handling system.

The CPCF sludge, like the $\mathrm{K}-1232$ sludge, was mixed inside of the drums by Energy Systems operations to make its removal easier. The CPCF sludge was much more fluid than the K-1232 sludge and flowed out of the drums even though it had a higher total solids content at $40 \%$ versus $29 \%$ for the pasty $\mathrm{K}-1232$ sludge.

The blockage of the gas system was first observed as a sharp increase in the pressure drop across the secondary condenser (HX-002) at about 1.5 to 2 hours into the run. This was initially diagnosed as a freeze up of the condenser, which was an event that had occurred in prior testing of the system. When corrective actions which had previously been employed to remedy freezing proved unsuccessful, it was realized that a new problem was encountered. At this time the primary condenser also indicated an increased pressure drop, and the vacuum at the recirculation blower inlet increased. The recirculation gas flow rate decreased despite attempts to maintain flow. It was decided to discontinue feed to the unit and proceed with an orderly shutdown.

An hour after shutting down the feed, gas recirculation flow was extremely low. At this time, essentially all moisture and organics had been removed from the dryer. A dryer pressure of $0.25 \mathrm{in}$. was maintained by a combination of the 
vacuum exerted by the eductor on the vent blower and the continued cooling provided by the scrubber. No releases, (neither radioactivity nor vapors) were observed from the system during the shutdown period. The gas system was disassembled, examined and cleaned.

It was observed that a black gelatinous organic material had accumulated inside the tubes of the primary condenser $(\mathrm{HX}-001)$ and its condensate pot. In addition, white crystals were growing on the condensate pot's baffle. A small amount of clay was found on the primary condenser inlet tube sheet, presumably from the two clay surrogate test runs. Subsequent analyses of the organic material failed to identify its major constituents. However, based on the high concentration of oil and grease in the feed, the known fact that phenol based synthetic hydraulic fluids were present in the waste, and the physical properties of phenol; it is a fairly good assumption that phenol crystallized in the condenser and blocked off the flow area.

Based on these results during the CPCF parameter setting run, and the inability to modify the gas handling system to accommodate the constituents of this waste stream within the demonstration schedule, a production run was not attempted for the CPCF sludge.

\section{$3.4 \quad$ Test Run Y-12-5}

Test run Y-12-5 was the first of two production runs on the K-1232 sludge. It was intended to be the only production run, however after feeding eleven of the remaining seventeen drums, the feed was stopped because of problems with the $\left(\right.$ Moyno $^{\mathrm{TM}}$ ) sludge feed pump. The problem was corrected and testing proceeded.

In order to achieve a product temperature of 600 to $650^{\circ} \mathrm{F}$, the dryer was operated with higher furnace temperatures in each zone than during the parameter setting run. Also, the residence time in the dryer was increased. A sludge feed rate of about 250 pounds/hour was targeted.

The test run proceeded as expected, with the product temperature in the desired range. During the run, the furnace temperature was increased above the initial settings periodically to account for variations in the moisture of the feed. On two occasions, water had to be added to the material at the bottom of the drums because it was too dry to feed through the $\mathrm{Moyno}^{\mathrm{TM}}$ pump. The added water totalled approximately 2.5 gallons. 
The operation of the system during this run could be described as routine. All equipment performed as expected. At 21 hours into the run, it was observed that the sludge pump was no longer feeding. After several unsuccessful attempts to reestablish feed, the pump was emptied and disassembled. A large portion of a polyethylene drum liner was removed from the pump's stator. The liner had been torn into pieces during the mixing of the sludge inside the storage drum, and was not observed when filling the pump feed hopper. It was also observed at this time that the pump's rubber stator had become either abraded or chemically degraded, because it had a large amount of slip on the pump's rotor. The system was secured and the test discontinued.

The Moyno ${ }^{\mathrm{TM}}$ pump stator had to be replaced prior to resumption of testing since feed could not be established. The stator was replaced from spare parts using one of identical construction. The replacement stator performed well through the remainder of the testing.

\subsection{Test Run Y-12-6}

Run Y-12-6 was the continuation of the Y-12-5 run and the completion of the production run for the $\mathrm{K}-1232$ sludge. The remaining six drums of this sludge were processed.

Dryer settings similar to those used for run Y-12-5 were used during this run. Product temperatures in the desired range were consistently achieved.

As during the previous run, it was necessary to add approximately two gallons of water to the bottom of one of the storage drums because the sludge was too dry to pump.

During the test run, it was observed that the pressure drop across the spray scrubber was increasing. To counteract this trend, the gas recirculation rate was reduced. The run continued as the pressure drop remained constant for the rest of the run. After the run, while cleaning the equipment, it was observed that solids had started to accumulate at the inlet to the spray scrubber. This was not a major problem and could be solved easily with the addition of wash-down nozzles in the affected area.

\subsection{DESCRIPTION OF PROBLEMS}


During the performance of the demonstration, there were a number of mechanical, procedural, and process-related problems. This section describes each of these problems and the corrective action taken, if any.

\section{Clay Surrogate Testing Phase}

- The gas reheater (HT-002) flamed out during run Y-12-1, caused by wind blowing into the discharge stack elbow. The elbow was replaced with a "Chinese hat."

- The product transfer conveyor jammed while sampling during run Y-12-1, caused by clay-absorbent chunks. The conveyor was jogged and restarted with no similar failure experienced during sludge processing.

- The product sample port released small amounts of product while taking samples during run Y-12-1. The sample port was enclosed inside a radiological glove bag with no further releases observed during sludge processing.

- Surrogate siudge splashed from the feed hopper when tipping the drum. To correct this, a splash shield was added to the hopper with no further problems encountered.

- The sludge lance plugged during run Y-12-2 start up: A $45^{\circ}$ elbow at the end of the lance allowed material to build up and cause an obstruction. The elbow was removed as it was not needed.

- The lump crusher was hitting the product thermocouple inside the dryer. The crusher was too long and the cylinder end dam not high enough. Six inches were removed from the lump crusher and a new end dam was welded into the dryer.

\section{$\underline{\text { K-1232 Parameter Setting Run }}$}

- The oxygen analyzer failed during checkout, most likely caused by moisture in the sensor head. The circuit board and sensor were replaced and the sensor heads sealed. No similar problems were noted.

- Minor leakage of moisture was observed from a feed drum when delivered from storage. Radiological surveys showed no transferrable radioactivity. The drum was returned to storage without incident. 
- Waste could not be removed from drums due to the unexpected thickness of the waste. The material had settled and consolidated in the drums after blending and during storage. The waste drums were returned to Energy Systems operations, where they were remixed with drum mixer. The waste was returned as a pumpable sludge.

- The cylinder drive failed due to a faulty variable frequency speed controller. It was replaced under warranty.

- The organic analyzer would not start up on one occasion due to a dirty detector. The detector was cleaned with no further problems noted.

- Test run stack sample analyses showed an airborne uranium level factor of two above background. A HEPA filter was installed on the process vent line to remove the uranium from stack emissions.

\section{CPCF Parameter Setting Run}

- The condensers became plugged with organic solids. The run was aborted, and the condensers were cleaned. No corrective action was taken to eliminate plugging due to time constraints. No CPCF production run was made.

\section{$\underline{\text { K-1232 Production Runs }}$}

- System power was inadvertently shut down by an Energy Systems maintenance technician. The unit failed in a safe condition with no detectable releases. The system was successfully restarted within five minutes.

- The Moyno ${ }^{\mathrm{TM}}$ sludge feed pump failed after processing 11 drums. A plastic drum liner was found stuck in the pump stator. The stator was also worn, probably from chemical attack. Feeding was stopped, and the stator was replaced from spare parts.

- Solids accumulated at the scrubber inlet causing an increased pressure drop across the scrubber. The operator decreased recirculation flow, and the run was completed without problem. 


\subsection{SUMMARY OF ANALYTICAL RESULTS}

All chemical and radiological analyses for the demonstration project was performed by the K-25 site Analytical Chemistry Department. All summaries presented in this section are based on these analytical results.

\subsection{Waste Characterization}

The waste that was treated during the demonstration was prepared by Energy Systems operations according to the methods described in the Sampling and Analyses Project Plan that was developed for the demonstration project. This involved selecting a representative number of sludge drums from the stored population, blending the selected drums while maintaining two distinct populations for the K-1232 and CPCF sludges, sampling and analyses to determine the degree of homogeneity, and then performing a full waste characterization for each population. 
The complete analytical results for the waste characterization have been summarized in Tables 5 and 6, along with the data for the treated product that resulted from $X^{*} T R A X^{\mathrm{TM}}$ processing. The reported value for the feed is the average of three values from the triplicate sampling. For the K-1232 waste, the product results are the average of two values from duplicate sampling during the production runs (Y-12-5 and Y-12-6). Each category of analyses has been sorted by species from the highest to lowest concentration. To shorten these tables, compounds that were reported to be below the detection limit are not listed. 
TABLE 5

SUMMARY OF ANALYTICAL RESULTS

K-1232 SLUDGE

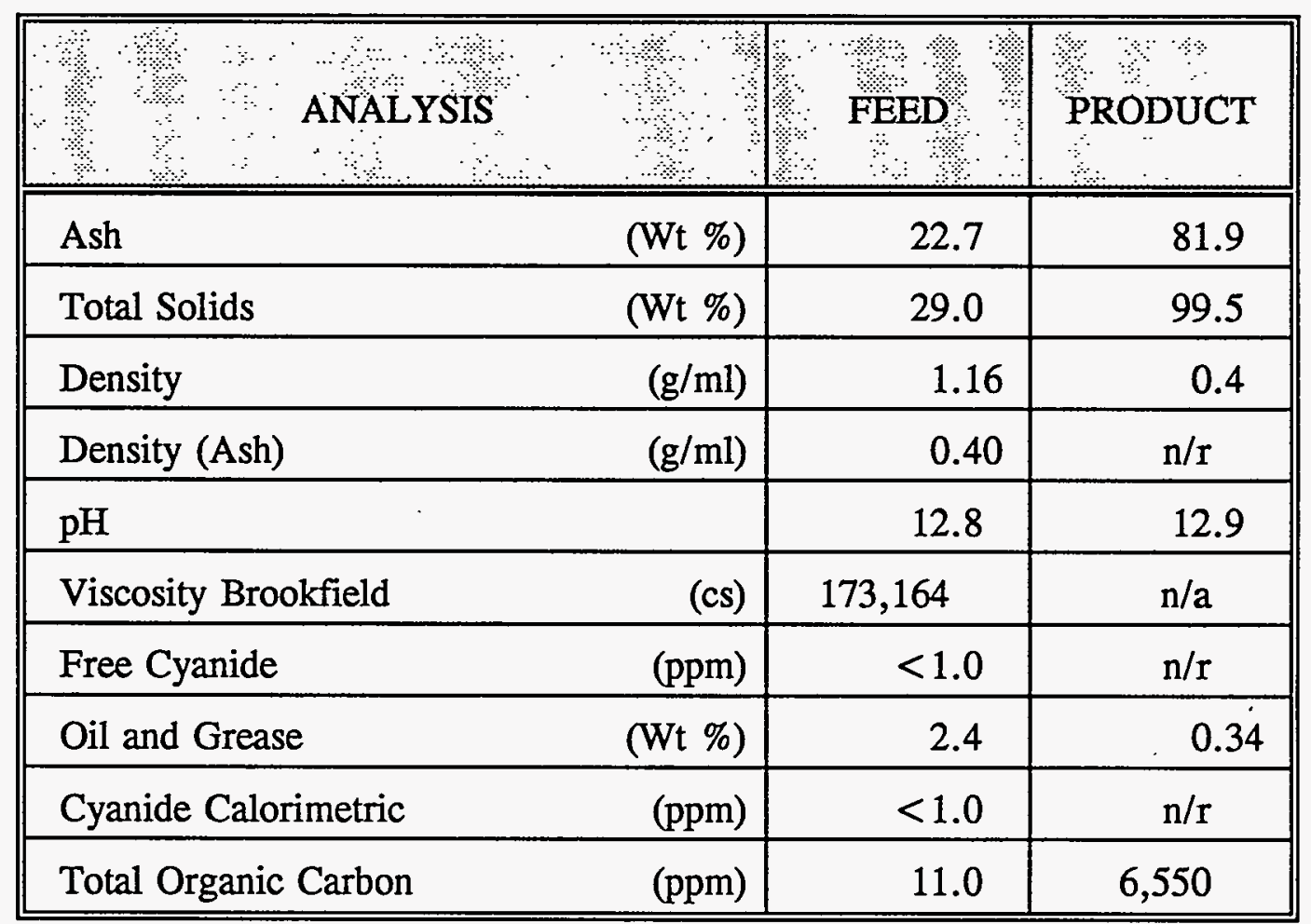

NOTES:

$$
\begin{aligned}
\mathrm{n} / \mathrm{a} & =\text { Analysis not applicable. } \\
\mathrm{n} / \mathrm{r} & =\text { Analysis not requested. } \\
\mathrm{nes} & =\text { Not enough sample. } \\
\mathrm{B} & =\text { Also found in reagent blank. } \\
\mathrm{J} & =\text { Indicates an estimated value. } \\
- & =\text { Analysis requested, no value reported. }
\end{aligned}
$$


TABLE 5 (Continued)

Summary of Analytical Results

K-1223 Sludge

\begin{tabular}{|c|c|c|c|}
\hline \multicolumn{4}{|c|}{ SEMT-VOLATILES } \\
\hline ANALYSIS & $\begin{array}{l}\text { FEED } \\
(\mathrm{ppm})\end{array}$ & $\begin{array}{c}\text { PRODUCT } \\
\text { (ppm) }\end{array}$ & $\begin{array}{c}\% \\
\text { REMOVAL }\end{array}$ \\
\hline Diacetone Alcohol & $266,693 \mathrm{BJ}$ & 5,654 & 97.9 \\
\hline Phenol & 22,267 & 600 & 97.3 \\
\hline 4-Methylphenol & 1,075 & 45 & 95.8 \\
\hline 2-Methylphenol & 900 & 17 & 98.1 \\
\hline Probable Phenolic \#3 & $452 \mathrm{~J}$ & 11 & 97.6 \\
\hline 2,4-Dimethylphenol & 223 & 20 & 91.0 \\
\hline Probable Phenolic \#4 & $165 \mathrm{~J}$ & 26 & 84.2 \\
\hline 3,3-Dichlorobenzidene & 120 & $\mathrm{n} / \mathrm{d}$ & $>94.4$ \\
\hline Bis (2-Chloroisopropyl) ether & 110 & $\mathrm{n} / \mathrm{d}$ & $>97.0$ \\
\hline Unknown \#3 & $107 \mathrm{~J}$ & $\mathrm{n} / \mathrm{a}$ & $\mathrm{n} / \mathrm{a}$ \\
\hline Benzoic Acid & 100 & nd & $>83.0$ \\
\hline Unknown \#1 & $78 \mathrm{~J}$ & $\mathrm{n} / \mathrm{a}$ & $\mathrm{n} / \mathrm{a}$ \\
\hline Probable Phenolic \#1 & $74 \mathrm{~J}$ & 6 & 92.5 \\
\hline Probable Phenolic \#2 & $41 \mathrm{~J}$ & 6 & 86.0 \\
\hline Probable Dimethylpentene & $29 \mathrm{~J}$ & $\mathrm{n} / \mathrm{a}$ & $\mathrm{n} / \mathrm{a}$ \\
\hline Unknown \#2 & $28 \mathrm{~J}$ & $\mathrm{n} / \mathrm{a}$ & $\mathrm{n} / \mathrm{a}$ \\
\hline 2-Methylnapthalene & $19 \mathrm{~J}$ & $\mathrm{n} / \mathrm{d}$ & $>82.9$ \\
\hline Bis (2-Ethylhexyl)phthalate & $14 \mathrm{BJ}$ & 3 & 80.0 \\
\hline Di-n-butylphthalate & $11 \mathrm{BJ}$ & 1 & 92.4 \\
\hline Acenaphthene & $4 \mathrm{~J}$ & $\mathrm{n} / \mathrm{d}$ & $>17.5$ \\
\hline Dibenzofuran & $3 \mathrm{~J}$ & $\mathrm{n} / \mathrm{d}$ & $\mathrm{n} / \mathrm{a}$ \\
\hline 4-Chloro-3-Methylphenol & $\mathrm{n} / \mathrm{d}$ & 1,100 & $\mathrm{n} / \mathrm{a}$ \\
\hline
\end{tabular}


TABLE 5 (Continued) Summary of Analytical Results

K-1223 Sludge

\begin{tabular}{|c|c|c|c|}
\hline$\because \quad \because \quad \%$ & E ORGANICS & 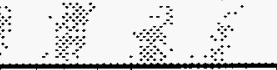 & $\because$ \\
\hline \% & $\begin{array}{l}\text { FEED } \\
(\text { PPM) }\end{array}$ & $\begin{array}{l}\text { PRODUCT } \\
\text { (PPM) }\end{array}$ & REMOVAL \\
\hline Tetrachloroethane & 2.40 & $\mathbf{n} / \mathbf{d}$ & $>89.6$ \\
\hline Methyl-Naphthalene & $1.35 \mathrm{~J}$ & 0.54 & 60.0 \\
\hline Probable Hydrocarbon \#2 & 0.73 & n/a & $\mathrm{n} / \mathbf{a}$ \\
\hline Acetone & 0.49 & 2.15 & undef \\
\hline Probable Hydrocarbon \#1 & 0.48 & n/a & $\mathbf{n} / \mathbf{a}$ \\
\hline Tolueneethylphenol & 0.42 & 0.63 & undef \\
\hline Prob Aromatic Hydrocarbon \#3 & $0.36 \mathrm{~J}$ & $\mathbf{n} / \mathbf{a}$ & $\mathrm{n} / \mathrm{a}$ \\
\hline Prob. Aromatic Hydrocarbon $\# 2$ & $0.28 \mathrm{~J}$ & n/a & $\mathbf{n} / \mathbf{a}$ \\
\hline Prob. Aromatic Hydrocarbon \#5 & $0.26 \mathrm{~J}$ & $\mathrm{n} / \mathbf{a}$ & $\mathrm{n} / \mathrm{a}$ \\
\hline Prob. Aromatic Hydrocarbon \#1 & $0.24 \mathrm{~J}$ & $\mathrm{n} / \mathbf{a}$ & $\mathrm{n} / \mathrm{a}$ \\
\hline Ethyl Benzene & $0.23 \mathrm{BJ}$ & nd & $\mathrm{n} / \mathrm{a}$ \\
\hline Prob. Aromatic Hydrocarbon \#6 & $0.23 \mathrm{~J}$ & $\mathrm{n} / \mathrm{a}$ & $\mathbf{n} / \mathbf{a}$ \\
\hline Prob. Aromatic Hydrocarbon \#4 & $0.22 \mathrm{~J}$ & $\mathrm{n} / \mathrm{a}$ & $\mathrm{n} / \mathrm{a}$ \\
\hline Prob. Aromatic Hydrocarbon $\# 7$ & $0.21 \mathrm{~J}$ & $\mathrm{n} / \mathrm{a}$ & $\mathrm{n} / \mathrm{a}$ \\
\hline Prob. Aromatic Hydrocarbon \#8 & $0.19 \mathrm{~J}$ & $\mathrm{n} / \mathbf{a}$ & $\mathrm{n} / \mathrm{a}$ \\
\hline 2-Butanone & 0.13 & 0.64 & undef \\
\hline Xylene (Total) & 0.09 & $\mathrm{n} / \mathrm{d}$ & $\mathrm{n} / \mathrm{a}$ \\
\hline Methylene Chloride & $0.02 \mathrm{BJ}$ & $\mathrm{n} / \mathrm{d}$ & $\mathrm{n} / \mathrm{a}$ \\
\hline Chloroform & $0.02 \mathrm{BJ}$ & $\mathrm{n} / \mathrm{d}$ & $\mathrm{n} / \mathrm{a}$ \\
\hline 2-Hexanonene & $0.01 \mathrm{~J}$ & $\mathrm{n} / \mathrm{d}$ & $\mathrm{n} / \mathrm{a}$ \\
\hline Trichloroathane & $0.01 \mathrm{~J}$ & $\mathrm{n} / \mathrm{d}$ & $\mathrm{n} / \mathrm{a}$ \\
\hline 1,1,1,-Trichloroethane & $0.01 \mathrm{BJ}$ & $\mathrm{n} / \mathrm{d}$ & $\mathrm{n} / \mathrm{a}$ \\
\hline 1,1,2,-Trichloroethane & $0.01 \mathrm{~J}$ & $\mathrm{n} / \mathrm{d}$ & $\mathrm{n} / \mathrm{a}$ \\
\hline Trans-1,3-Dichloropropene & $0.01 \mathrm{~J}$ & $\mathrm{n} / \mathrm{d}$ & $\mathrm{n} / \mathrm{a}$ \\
\hline Carbon Disulfide & $0.01 \mathrm{~J}$ & $\mathrm{n} / \mathrm{d}$ & $\mathrm{n} / \mathrm{a}$ \\
\hline Benzene & $0.01 \mathrm{~J}$ & 3.25 & undef \\
\hline
\end{tabular}


TABLE 5 (Continued)

Summary of Analytical Results

K-1223 Sludge

\begin{tabular}{|c|c|c|}
\hline \multicolumn{3}{|c|}{ METALS } \\
\hline ANALYSIS & $\begin{array}{l}\text { FEED } \\
\text { (PPM) }\end{array}$ & $\begin{array}{c}\text { PRODUCT } \\
\text { (PPM) }\end{array}$ \\
\hline Calcium & 326,667 & 380,000 \\
\hline Phosphorous & 26,667 & 31,000 \\
\hline Iron & 17,667 & 21,000 \\
\hline Potassium & 9,667 & 13,000 \\
\hline Aluminum & 8,533 & 9,200 \\
\hline Nickel & 8,200 & 9,600 \\
\hline Sodium & 4,833 & 4,900 \\
\hline Magnesium & 4,000 & 4,900 \\
\hline Silicon & 627 & 450 \\
\hline Chromium & 483 & 540 \\
\hline Zinc & 430 & 590 \\
\hline Lead & 373 & 610 \\
\hline Manganese & 303 & 360 \\
\hline Boron & 223 & 210 \\
\hline Copper & 97 & 130 \\
\hline Titanium & 58 & 77 \\
\hline Lithium & 56 & 56 \\
\hline Barium & 41 & 45 \\
\hline Cobalt & 28 & 38 \\
\hline Molybdenum & 22 & $<10$ \\
\hline Beryllium & 11 & 11 \\
\hline Cadmium & 7.1 & 9.2 \\
\hline Mercury & 5.2 & $\mathrm{n} / \mathrm{a}$ \\
\hline Arsenic & 2.3 & $\mathbf{n} / \mathbf{a}$ \\
\hline Thorium & $<200.0$ & 240 \\
\hline
\end{tabular}


TABLE 5 (Continued)

Summary of Analytical Results

K-1223 Sludge

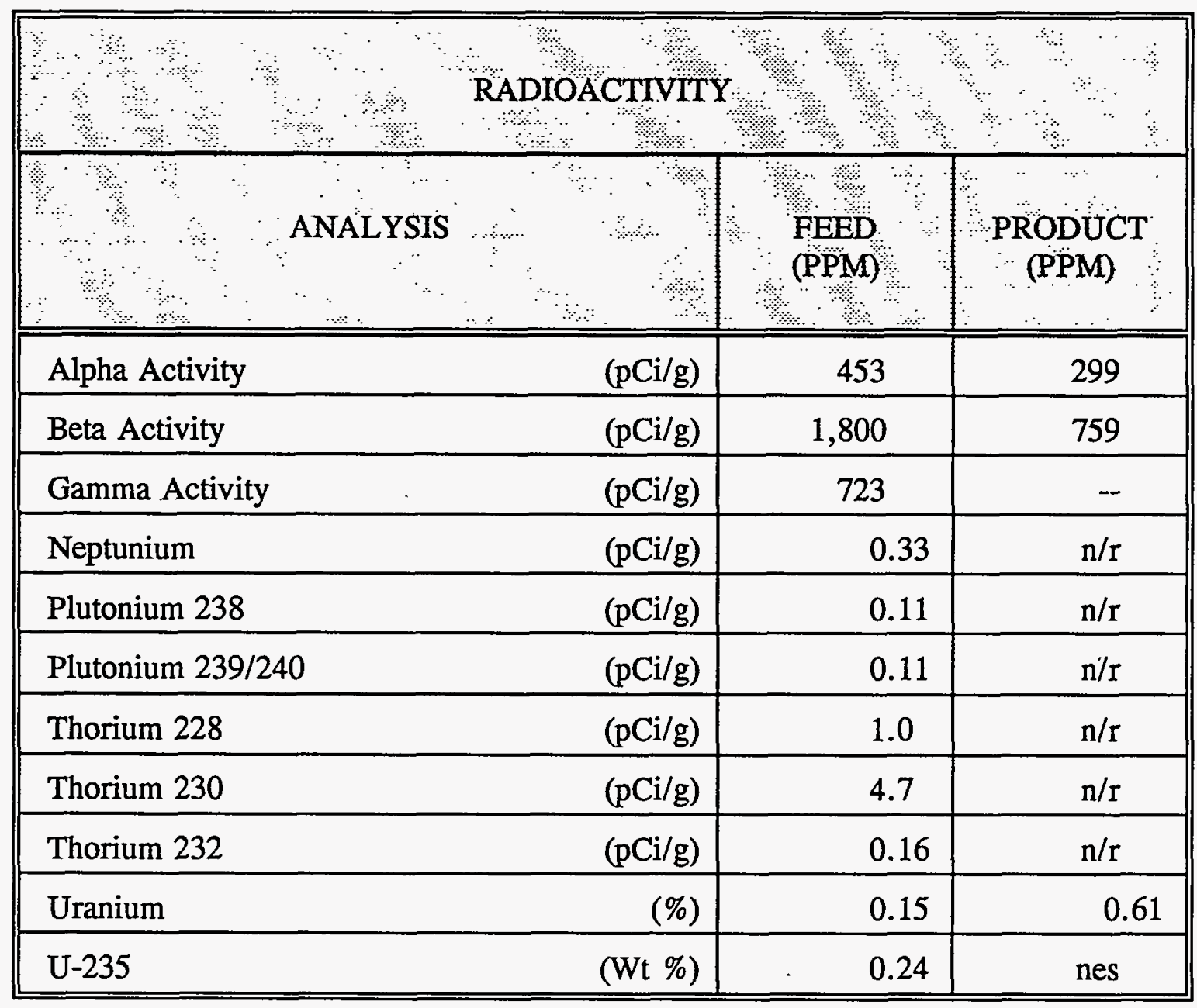


TABLE 6

SUMMARY OF ANALYTICAL RESULTS

CPCF SLUDGE

\begin{tabular}{||lr|r|c||}
\hline \multicolumn{1}{|c|}{ ANALYSIS } & \multicolumn{1}{c||}{ FEED } & PRODUCT \\
\hline \hline Ash & $(\mathrm{Wt} \%)$ & 24.8 & $\mathrm{n} / \mathrm{r}$ \\
\hline Total Solids & $(\mathrm{Wt} \%)$ & 40.3 & 98.8 \\
\hline Density & $(\mathrm{g} / \mathrm{ml})$ & 1.21 & 0.45 \\
\hline Density (Ash) & $(\mathrm{g} / \mathrm{ml})$ & 0.48 & $\mathrm{n} / \mathrm{r}$ \\
\hline $\mathrm{pH}$ & & 7.2 & $\mathrm{n} / \mathrm{r}$ \\
\hline Viscosity Brookfield & $(\mathrm{cs})$ & 165,978 & $\mathrm{n} / \mathrm{r}$ \\
\hline Free Cyanide & $(\mathrm{ppm})$ & $<1.0$ & $\mathrm{n} / \mathrm{r}$ \\
\hline Oil and Grease & $(\mathrm{Wt} \%)$ & 25.2 & 6.44 \\
\hline Cyanide Calorimetric & $(\mathrm{ppm})$ & $<1.0$ & $\mathrm{n} / \mathrm{r}$ \\
\hline Total Organic Carbon & $(\mathrm{ppm})$ & 5.7 & $\mathrm{n} / \mathrm{r}$ \\
\hline
\end{tabular}

NOTES:
$\mathrm{n} / \mathrm{a}=$ Analysis not applicable.
$\mathrm{n} / \mathrm{r}=$ Analysis not requested.
nes $=$ Not enough sample.
B $=$ Also found in reagent blank.
$\mathrm{J}=$ Indicates an estimated value.
-- $\quad=$ Analysis requested, no value reported. 
TABLE 6 (Continued)

Summary of Analytical Results

CPCF Sludge

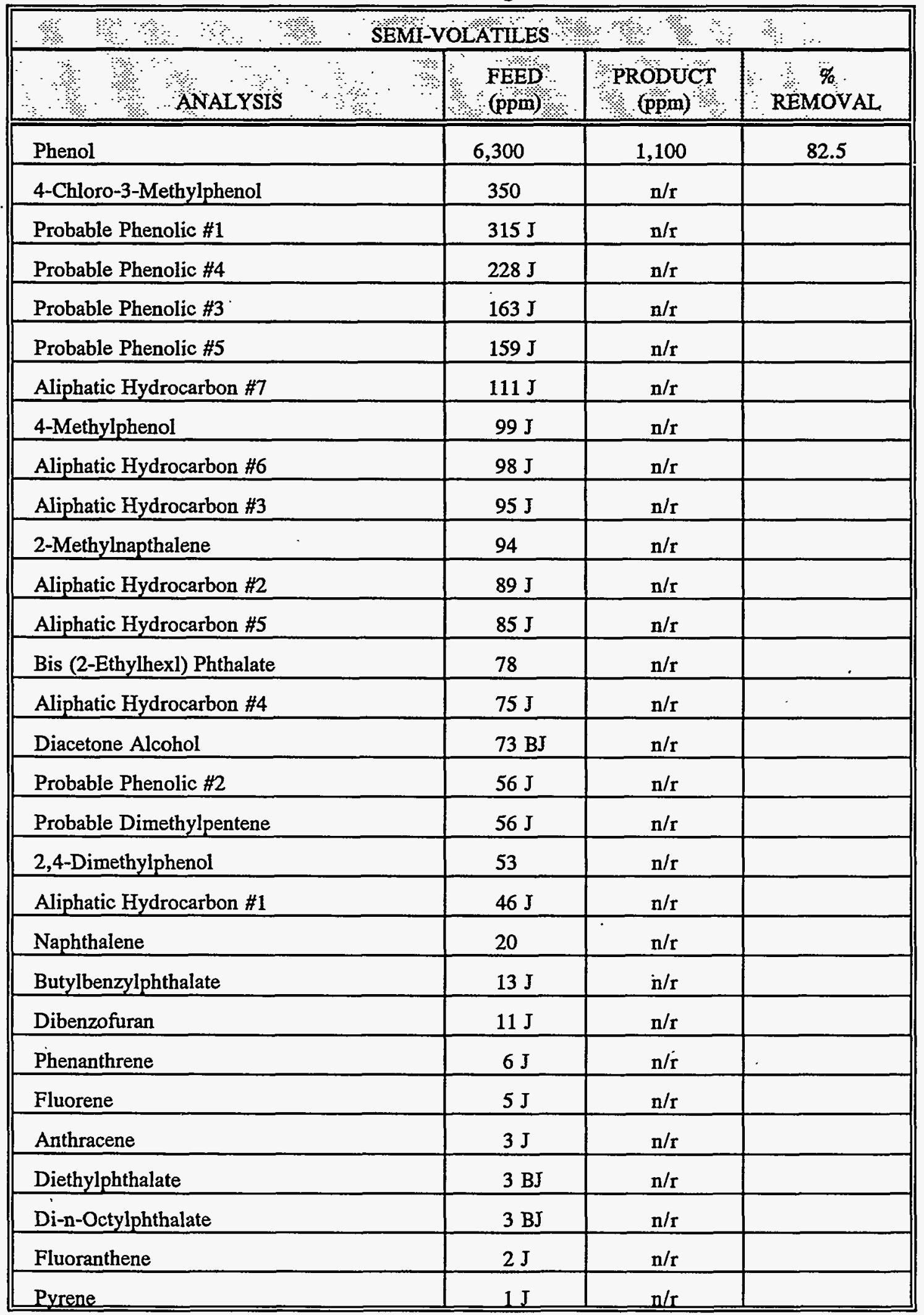


TABLE 6 (Continued)

Summary of Analytical Results

CPCF Sludge

\begin{tabular}{|l|c|c|c||}
\hline \multicolumn{4}{|c|}{ VOLATILE ORGANICS } \\
\hline & $\begin{array}{c}\text { FEED } \\
\text { (PPM) }\end{array}$ & $\begin{array}{c}\text { PRODUCT } \\
\text { (PPM) }\end{array}$ & $\begin{array}{c}\% \\
\text { REMOVAL }\end{array}$ \\
\hline \hline Probable Hydrocarbon \#1 & 29.5 J & $\mathrm{n} / \mathrm{r}$ & \\
\hline Probable Hydrocarbon \#2 & $16.5 \mathrm{~J}$ & $\mathrm{n} / \mathrm{r}$ & \\
\hline Tetrachloroethane & 5.9 & $\mathrm{n} / \mathrm{r}$ & \\
\hline Prob. Aromatic Hydrocarbon \#4 & $4.7 \mathrm{~J}$ & $\mathrm{n} / \mathrm{r}$ & \\
\hline Prob. Aromatic Hydrocarbon \#3 & $3.8 \mathrm{~J}$ & $\mathrm{n} / \mathrm{r}$ & \\
\hline Prob. Aromatic Hydrocarbon \#5 & $3.7 \mathrm{~J}$ & $\mathrm{n} / \mathrm{r}$ & \\
\hline Prob. Aromatic Hydrocarbon \#2 & $3.5 \mathrm{~J}$ & $\mathrm{n} / \mathrm{r}$ & \\
\hline Prob. Aromatic Hydrocarbon \#1 & $2.8 \mathrm{~J}$ & $\mathrm{n} / \mathrm{r}$ & \\
\hline Prob. Aromatic Hydrocarbon \#8 & $2.4 \mathrm{~J}$ & $\mathrm{n} / \mathrm{r}$ & \\
\hline Prob. Aromatic Hydrocarbon \#7 & $2.4 \mathrm{~J}$ & $\mathrm{n} / \mathrm{r}$ & \\
\hline Prob. Aromatic Hydrocarbon \#6 & $2.0 \mathrm{~J}$ & $\mathrm{n} / \mathrm{r}$ & \\
\hline Acetone & $2.0 \mathrm{~B}$ & $\mathrm{n} / \mathrm{r}$ & \\
\hline Xylene (total) & $0.6 \mathrm{~B}$ & $\mathrm{n} / \mathrm{r}$ & \\
\hline Ethyl Benzene & $0.6 \mathrm{~B}$ & $\mathrm{n} / \mathrm{r}$ & \\
\hline Methylene Chloride & $0.4 \mathrm{~B}$ & $\mathrm{n} / \mathrm{r}$ & \\
\hline 1,1,1-Trichloroethane & $0.3 \mathrm{~B}$ & $\mathrm{n} / \mathrm{r}$ & \\
\hline Chloroform & $0.3 \mathrm{BJ}$ & $\mathrm{n} / \mathrm{r}$ & \\
\hline 1,1-Dichloroethane & 0.3 & $\mathrm{n} / \mathrm{r}$ & \\
\hline Toluene & $0.2 \mathrm{~J}$ & $\mathrm{n} / \mathrm{r}$ & \\
\hline Styrene & $0.0 \mathrm{~J}$ & $\mathrm{n} / \mathrm{r}$ & \\
\hline Trichloroethane & $0.0 \mathrm{~J}$ & $\mathrm{n} / \mathrm{r}$ & \\
\hline Bromodichloromethane & $0.0 \mathrm{BJ}$ & $\mathrm{n} / \mathrm{r}$ & \\
\hline \hline
\end{tabular}


TABLE 6 (Continued)

Summary of Analytical Results

CPCF Sludge

\begin{tabular}{|c|c|c|c|}
\hline \% & १ METALS & मै: \% : & 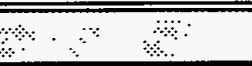 \\
\hline ANALYYSIS & $\begin{array}{l}\text { FEED } \\
\text { (PPM) }\end{array}$ & $\begin{array}{l}\text { PRODUCT } \\
\text { (PPM) }\end{array}$ & REMOVAL \\
\hline Calcium & 72,667 & $\mathrm{n} / \mathrm{r}$ & \\
\hline Iron & 69,333 & $\mathrm{n} / \mathbf{r}$ & \\
\hline Aluminum & 15,667 & $n / \mathbf{r}$ & \\
\hline Phosphorous & 6,000 & $n / \mathbf{r}$ & \\
\hline Magnesium & 2,100 & $\mathbf{n} / \mathbf{r}$ & \\
\hline Potassium & 1,667 & $n / x$ & \\
\hline Sodium & 1,600 & $n / r$ & \\
\hline Nickel & 1,400 & $\mathrm{n} / \mathrm{r}$ & \\
\hline Zinc & 863 & $\mathrm{n} / \mathrm{r}$ & \\
\hline Copper & 467 & $\mathrm{n} / \mathrm{r}$ & \\
\hline Silicon & 437 & $\mathrm{n} / \mathrm{r}$ & \\
\hline Lithium & 243 & $n / r$ & \\
\hline Manganese & 220 & $\mathrm{n} / \mathbf{r}$ & \\
\hline Boron & 190 & $\mathrm{n} / \mathrm{r}$ & \\
\hline Molybdenum & 133 & $\mathrm{n} / \mathrm{r}$ & \\
\hline Barium & 95 & $\mathrm{n} / \mathrm{r}$ & \\
\hline Chromium & 84 & $\mathrm{n} / \mathrm{r}$ & \\
\hline Titanium & 41 & $n / r$ & \\
\hline Zirconium & 38 & $n / r$ & \\
\hline Beryllium & 27 & $\mathrm{n} / \mathrm{r}$ & \\
\hline Cobalt & 25 & $\mathrm{n} / \mathrm{r}$ & \\
\hline Strontium & 13 & $\mathrm{n} / \mathrm{r}$ & \\
\hline Cadmium & 10.8 & $n / r$ & \\
\hline Mercury & 8.8 & $\mathrm{n} / \mathrm{r}$ & \\
\hline Vanadium & 5.4 & $\mathrm{n} / \mathrm{r}$ & \\
\hline Arsenic & 2.9 & $\mathrm{n} / \mathrm{r}$ & \\
\hline Thorium & $<200.0$ & $\mathrm{n} / \mathrm{r}$ & \\
\hline Lead & $<50.0$ & $\mathrm{n} / \mathrm{r}$ & \\
\hline Niobium & $<7.0$ & $\mathrm{n} / \mathrm{r}$ & \\
\hline Silver & $<6.0$ & $\mathrm{n} / \mathrm{r}$ & \\
\hline \begin{tabular}{|c|c|} 
Selenium \\
\end{tabular} & $<0.5$ & $n / r$ & \\
\hline
\end{tabular}


TABLE 6 (Continued)

Summary of Analytical Results

CPCF Sludge

\begin{tabular}{|c|c|c|c|}
\hline \multicolumn{4}{|c|}{ RADIOACTIVITY } \\
\hline & & $\begin{array}{l}\text { FEED } \\
(P P M)\end{array}$ & $\begin{array}{l}\text { PRODUCT } \\
\text { (PPM) }\end{array}$ \\
\hline Alpha Activity & $(\mathrm{pCi} / \mathrm{g})$ & 2,167 & $\mathrm{n} / \mathrm{r}$ \\
\hline Beta Activity & $(\mathrm{pCi} / \mathrm{g})$ & 5,700 & $\mathrm{n} / \mathrm{r}$ \\
\hline Gamma Activity & $(\mathrm{pCi} / \mathrm{g})$ & 3,333 & $\mathrm{n} / \mathrm{r}$ \\
\hline Neptunium & (pCi/g) & 7.0 & $\mathrm{n} / \mathrm{r}$ \\
\hline Plutonium 238 & $(\mathrm{pCi} / \mathrm{g})$ & 0.27 & $\mathrm{n} / \mathrm{r}$ \\
\hline Plutonium 239/240 & $(\mathrm{pCi} / \mathrm{g})$ & 0.07 & $\mathrm{n} / \mathrm{r}$ \\
\hline Thorium 228 & $(\mathrm{pCi} / \mathrm{g})$ & 7.3 & $\mathrm{n} / \mathrm{r}$ \\
\hline Thorium 230 & $(\mathrm{pCi} / \mathrm{g})$ & 11.7 & $\mathrm{n} / \mathrm{r}$ \\
\hline Thorium 232 & (pCi/g) & 0.56 & $\mathrm{n} / \mathrm{r}$ \\
\hline Uranium & $(\%)$ & 0.44 & $\mathrm{n} / \mathrm{r}$ \\
\hline U-235 & (Wt \%) & 0.33 & $n / r$ \\
\hline
\end{tabular}


Because the list of analyses is quite lengthy, the parameters of the feed that are of most relevance to the performance of the $\mathrm{X}^{*} \mathrm{TRAX}{ }^{\mathrm{TM}}$ system have been summarized in Table 7.

TABLE 7

Y-12 Sludge Feed Analysis Summary

ANALYSIS

Total Solids (\%)

Density (g/ml)

Oil \& Grease - as received (\%)

Phenol (ppm)

Other Semi-volatiles (ppm)

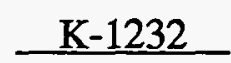

29.0

1.16

2.4

22,667

3,453
$\underline{\mathrm{CPCF}}$

403

R.

252

6,300

2,400

\subsection{Treated Product}

The key analytical results for the treated product from both the parameter setting runs and the K-1232 production runs have been summarized in Table 8. Significant improvement in both the drying and organic removal was made between the K-1232 parameter setting run and the subsequent production run. This improvement was the result of selecting appropriate dryer operating conditions based on the experience and data from the K-1232 parameter setting run. Both the product residence time and the dryer shell temperatures were increased for the production run. These changes resulted in a lower final moisture, oil and grease, and phenol content in the treated solids. A significant reduction in the organic content of the CPCF sludge was made in the aborted parameter setting run. 
TABLE 8

Treated Product - Key Results

PRODUCT ANALYSIS

Solids In

Product (\%)

Oil \& Grease

$95.2 \& 98.4$

$\%$ Removal

$(-3.3) \& 43.2$

\% Removal

K-1232 PARAMETER

SETTING RUN

K-1232 PRODUCTION

CPCF PARAMETER

SETTING RUN

$\mathrm{CPCF}$

99.95

85.8

99.6

98.8

74.4

92.9

\section{$5.3 \quad$ Residuals}

The scrubber's phase separator blowdown, the organic condensate, and the aqueous condensate were all sampled and analyzed for the K-1232 production run. These analytical results have been summarized in Table 9. 
TABLE 9

\section{Residuals Analyses Summary}

Phase

Condensate

Separator

\begin{tabular}{|c|c|c|c|c|}
\hline Analysis & Units & Blowdown & $\underline{\text { Organic }}$ & Water \\
\hline Total Solids & $\mathrm{mg} / 1$ & - & $n / \pi$ & 270 \\
\hline Suspended Solids & $\mathrm{mg} / \mathrm{l}$ & -- & $\mathrm{n} / \mathrm{r}$ & 131 \\
\hline Dissolved Solids & $\mathrm{mg} / 1$ & - & $\mathrm{n} / \mathrm{r}$ & 84 \\
\hline Ash & $\%$ & - & 0.23 & $\mathrm{n} / \mathrm{r}$ \\
\hline Water & $\%$ & $\mathrm{n} / \mathrm{r}$ & 67.5 & $\mathrm{n} / \mathrm{a}$ \\
\hline Alpha-Activity & $\mathrm{pCi} / 1$ & nes & 25,202 & 62 \\
\hline Beta-Activity & $\mathrm{pCi} / 1$ & nes & 50,950 & 120 \\
\hline Gamma-Activity & $\mathrm{pCi} / 1$ & nes & -- & -- \\
\hline Oil \& grease & $\%$ & 19.5 & $\mathrm{n} / \mathrm{r}$ & B \\
\hline TOC & ppm & - & $\mathrm{n} / \mathrm{r}$ & 431 \\
\hline Uranium & $\mathrm{mg} / \mathrm{g}$ & - & 95 & $<1$ \\
\hline $\begin{array}{c}\text { NOTES: nes } \\
\text { n/r } \\
\text { n/a } \\
--\end{array}$ & \multicolumn{4}{|c|}{$\begin{array}{l}\text { - Not enough sample } \\
\text { - Analysis not requested } \\
\text { - Analysis not applicable } \\
\text { - Analysis requested, no }\end{array}$} \\
\hline
\end{tabular}

\subsection{Solidified Product}

The treated $\mathrm{K}-1232$ sludge was not solidified as was intended according to the project plan. This was primarily based on budgetary limitations. An alternate plan was developed to remove samples of the product from the bins for leach testing. The K-1232 treated product was successfully solidified using a proprietary CNSI formula which was successful in stabilizing the contaminants of concern. This portion of the program consisted of bench scale testing of three cementatious binder formulas. The test specimen (prepared for TCLP and EPTox tests) provided a range of waste loadings from $15.6 \%$ (sample 8889-1) to $32.1 \%$ (sample 8889-3). The term waste loading is defined as the weight of waste/weight of total solidified sample. As an F006 listed waste, the 
contaminants presented in Table 10 were evaluated for leaching characteristics in accordance with the TCLP procedure specified in 40CFR 268.

TABLE 10

Leach Test Results

For Solidified K-1232 Product

Sample

3

$(\mathrm{mg} / \mathrm{l}) \stackrel{\text { Contaminant }}{\text { Cyanides (Amenable) }}$

Sample

Cadmium

$<0.03$

Chromium (Total)

$<0.18$

Lead

$<0.004$

Nickel

$<0.10$

Silver

$<0.10$

Cyanides (Total)

$<0.10$

Cyanides (Amenable)

K048-52 TCLP

Contaminant

Phenol
Regulatory

Sample Sample

Limit*

8889-1 8889-2

(mg/1)

$(\mathrm{mg} / \mathrm{l}) \quad(\mathrm{mg} / \mathrm{l})$

Regulatory Sample Sample

0.066

$<0.03<0.03$

5.2

$<0.10$

$<0.10$

0.51

$<0.004$

0.0057

0.32

$<0.10$

$<0.10$

0.072

$<0.10$

$<0.10$

590

$<0.10$

$<0.10$ 
Martin Marietta Energy Systems

Y-12 Sludge Detoxification Demonstration Final Report

* 40 CFR 268.41 (a)

Since there is no F006 constituent concentration limit for phenol, the most restrictive listed waste leachate value for phenol was chosen for evaluation. This value is reported under the K048-52 listed waste category, with a limit of 2.7 $\mathrm{mg} / \mathrm{l}$. Based on this criteria, samples 8889-1 and 8889-2 are within the land ban treatment standards. As mentioned above, the three waste loadings were chosen to evaluate the effect on leachate properties; therefore, sample 8889-3 would not be acceptable based on the phenol results. This information establishes the upper limit of the formula waste loading for this particular waste. In addition to the data summarized in Table 10, EP-Tox data was collected and all results were less than published limits. CNSI's assessment of the results for immobilization of the residue contaminants are very positive, and should prove to be valuable for a delisting petition.

6.0 DISCUSSION OF PROCESS EMISSIONS AND VOLUMETRIC RESIDUE CHANGES

The data collected with the process monitoring equipment, the vent gas sample analyses and the radiological monitoring program showed that the demonstration was carried out with negligible emissions to the environment.

The total organic levels in the vent were consistently below the permitted levels as discussed previously in Section 3.0. The analysis of the vent samples taken during runs Y-12-3 and Y-12-5 showed all volatile organics to be below their detection limits. A very small amount of uranium was detected in the process vent during the $\mathrm{K}-1232$ parameter setting run, Y-12-3. This was eliminated by the installation of a HEPA filter in this line. All radiological surveys of the general area and of the vent line showed only background radiation levels, indicating that there was no radioactivity released to the area during the demonstration. All of these data indicate that the process and administrative controls worked as intended and that the "zero release" objective of the demonstration was met.

During the demonstration the mixed waste sludges were processed through the $\mathrm{X}^{*} \mathrm{TRAX}^{\mathrm{TM}}$ system and the resulting treatment residuals were:

1. Dry treated solids

2. Phase separator blowdown liquid 
3. Condensed water and organics

Secondary waste streams generated during the demonstration were spent cartridge filters from the process vent filter, spent carbon filters from the process vent, and contaminated clothing and other trash (DAW). Decontamination solutions and contaminated equipment were also generated during the cleanup portion of the demonstration.

Table 11 is a summary of the volume of $\mathrm{K}-1232$ waste treated and the treatment residuals. Review of the data indicates that a large increase in the total volume of the waste was realized; however, this is not necessarily the case when the fate of the treatment residuals is considered. CNSI's experience indicates that DAW generation from a limited operation such as the sludge detoxification program could be much higher than for a long term operation with the establishment of more permanent contamination controls. 


\section{TABLE 11 \\ Waste Volume Changes \\ K-1232 Waste}

$\begin{array}{llc}\text { Description } & \text { Amount } & \text { Volume }\left(\mathrm{ft}^{3}\right) \\ \text { Waste Feed } & 24 \mathrm{drums} & 180^{*} \\ \text { Treated Dried Product } & 2940 \mathrm{lb} & 118 \\ \text { Water Condensed from Waste } & 966 \mathrm{gal} & 130 \\ \text { Phase Separator Blowdown } & 186 \mathrm{gal} & 25 \\ \text { Scrubber Makeup } & 324 \mathrm{gal} & 43 \\ \text { Total Water } & 1476 \mathrm{gal} & 198 \\ & & \\ \text { Commercial burial volume, actual waste volume }=153 \mathrm{ft}^{3} \text {, assuming } 85 \% \text { drum }\end{array}$
fill.

\subsection{DECONTAMINATION}

Prior to initiating the actual tests, CNSI had several meetings with Energy Systems on decontamination of the equipment. It was shortly before testing began that release limits were established. These limits for unconditional release were:

- Transferable Radiation - $2000 \mathrm{dpm} / \mathrm{cm}^{2}$ for alpha activity

- Fixed Radiation - 1000 dpm/direct probe for alpha activity

It was established that CNSI would perform the initial decontamination effort. Any vendor components which did not meet the release criteria would be sent to the Energy Systems decontamination facility for additional treatment.

Prior to moving the equipment onsite, an area survey was performed. This survey was repeated after removal of the system and no significant change was noted. Success in this area was due to a fire retardant polywoven sheeting which was installed on the ground before setting up the equipment. 
After testing was completed, decontamination efforts began. Compactible materials including poly sheeting were placed in drums. All peripheral systems (nitrogen, air conditioning condenser, bottled gas, etc.) were surveyed and free released. The stainless steel feed table, drum tipper, and vent piping were released. Disassembly of the feed pump was required, and the pump stator was scrapped as low level waste, however, the pump body was released.

The dryer and gas trailers were systematically disassembled. A number of components and piping were sent to Energy Systems for additional treatment. A portion of these components could not be adequately surveyed, or it was judged that the decontamination time was not justifiable. Some of that equipment was:

1. Heat Exchanger Tube Bundle No. 1

2. Heat Exchanger Tube Bundle No. 2

3. Phase Separator Pump

4. Phase Separator Plate Packs

5. Spray Tower Demister Pad

6. Sprays - (2)

7. Basket Strainer

8. Keckley Float Valve

9. Flow Switch

10. Brooks Flowmeters (2)

11. Three Piece Ball Valves (3)

12. Miscellaneous Black Pipe and Fittings

13. Miscellaneous Gaskets \& Bolts

The major component of the dryer, the cylinder, was cleaned and vacuumed. Repeated attempts still did not reduce the contamination to an acceptable level. Approximately 30 gallons of water were used to complete the task.

With the exception of the above mentioned equipment and the secondary product conveyor, the rest of the system was released.

This demonstration verified that the $\mathrm{X} * \mathrm{TRAX} \mathrm{X}^{\mathrm{TM}}$ thermal treatment system can be used to process mixed wastes and then be decontaminated such that the equipment could be relocated to another site. 


\subsection{COST ISSUES}

From the data gathered during the demonstration on throughput rates, residual quantities and qualities, a cost estimate has been prepared for treatment of the $\mathrm{K}$ 1232 sludge.

This estimate assumes that a unit of capacity similar to the Pilot $\mathrm{X}^{*} \mathrm{TRAX}^{\mathrm{TM}}$ system would be used as the production treatment system. It would be operated continuously, with outages every two (2) to four (4) weeks for routine maintenance. Assuming that the unit availability was about $80 \%, 3000$ drums per year of K-1232 waste could be processed with such a unit.

Table 12 is a summary of the major cost components of the treatment cost for the $\mathrm{K}-1232$ sludge.

TABLE 12

K-1232 Sludge

\section{Treatment/Disposal Cost Estimate Summary}

Item

Labor

Maintenance

Consumables

Disposal of non-Product Residues

Solidification/Burial of Product

Capital Charges

Site Preparation

Total
Cost *

(\$/drum of feed)

266.00

23.75

59.02

79.97

455.25

23.75

7.92

915.66

* 1989 Dollars 
There are a number of assumptions that were made in the development of this cost estimate. They are as follows:

- The condensed water is managed on-site at the CPCF at a cost of $\$ 2 /$ gallon.

- The phase separator blowdown is filter pressed and the filter cake is incinerated on-site at the TSCA incinerator at a cost of $\$ 0.50$ /pound.

- The dried product is solidified and disposed of off-site at a commercial lowlevel radioactive waste facility. The 1989 disposal fees at Barnwell, SC were used.

- Each feed drum contains 475 pounds of waste, net.

\subsection{DELISTING}

As shown in Section 5.4, the solidified K-1232 product meets all of the land ban criteria for an F006 waste. Since F006 gives no concentration limits for phenol, it would be prudent to select a waste category which does exhibit phenol limits for Toxicity Characteristics Leaching Procedure (TCLP) testing and compare the results against those limits.

Of the three solidification formulations selected, two of the waste loadings demonstrated leach properties lower than the K048-52 land ban limits (1.5 ppm for sample 8889-2 and $1.7 \mathrm{ppm}$ for sample 8889-1). Only the highest waste loading formula exceeded those limits. Earlier evaluations of the solidified product on dried samples of the K-1232 sludge prepared by J. E. Shoemaker of Energy Systems exhibited average leach index values of 7.7 for Cesium. These samples were spiked with Cesium and tested in accordance with the ANS 16.1 procedure. All leach index values for Cesium were well above the 6.0 specified by 10CFR 61. Compressive strengths of these test samples ranged from $1942 \mathrm{psi}$ for an $18.5 \mathrm{wt} . \%$ waste solids to $944 \mathrm{psi}$ for $34.1 \mathrm{wt} . \%$ waste solids.

The above results demonstrate that the treated, solidified $\mathrm{K}$ - 1232 sludge would meet the 10CFR 61 disposal leach criteria and, for two waste loadings, could be strong candidates in a successful EPA delisting petition. 


\section{INTERNAL DISTRIBUTION}

$\begin{aligned} \text { 1. } & \text { Bailey, J. K. } \\ \text { 2. } & \text { Begovich, J. M. } \\ \text { 4. } & \text { Bell, J. T. } \\ \text { 5. } & \text { Bostick, W. D. } \\ \text { 6. } & \text { Byers, C. H. } \\ \text { 7. } & \text { Clancey, H. M. } \\ \text { 8. } & \text { Collins, E. D. } \\ \text { 9. } & \text { Conner, G. D. } \\ \text { 10. } & \text { Craig, R. B. } \\ \text { 11. } & \text { Croff, A. G. } \\ \text { 12. } & \text { Cutshall, N. H. } \\ \text { 13. } & \text { Delozier, M. P. } \\ \text { 14. } & \text { Fulkerson, W. } \\ \text { 15. } & \text { Genung, R. K. } \\ \text { 16. } & \text { Gross, R. M. } \\ \text { 17. } & \text { Hightower, J. R. } \\ \text { 18. } & \text { Johnson, E. K. } \\ \text { 19-38. } & \text { Jolley, R. L. } \\ & \end{aligned}$

$\begin{aligned} \text { 39-58. } & \text { Kennerly, J. M. } \\ 59 . & \text { Kirkpatrick, C. R. } \\ 60 . & \text { Malinauskas, A. P. } \\ 61 . & \text { McNeese, L. E. } \\ 62 . & \text { Meacham, S. A. } \\ 63 . & \text { Patton, B. D. } \\ 64 . & \text { Petty, J. R. } \\ 65 . & \text { Prazniak, J. K. } \\ 66 . & \text { Reichle, D. R. } \\ 67 . & \text { Robinson, S. M. } \\ 68 . & \text { Shoemaker, J. L. } \\ \text { 69-88. } & \text { Singh, S. P. N. } \\ 89 . & \text { Walker, R. L. } \\ 90 . & \text { Central Research Library } \\ 91 . & \text { ORNL - Y-12 Technical Library } \\ & \text { Document Reference Section } \\ \text { 92-93. } & \text { Laboratory Records } \\ 94 . & \text { Laboratory Records, ORNL RC } \\ 95 . & \text { ORNL Patent Section }\end{aligned}$

\section{EXTERNAL DISTRIBUTION}

96. W. D. Adams, Assistant Manager, Environmental Restoration and Waste Management, P. O. Box 2001, Oak Ridge, Tennessee 37831

97. J. C. Hall, Assistant Manager for Energy Research and Development, P. O. Box 2001, Oak Ridge, Tennessee 37831

98. P. E. Hollenbeck, 31 Pelican Circle, Panama City, Florida 32413

99. R. O. Hultgren, Deputy Assistant Manager for Energy Research and Development, Oak Ridge National Laboratory, P. O. Box 2008, Oak Ridge, Tennessee 37831-6269

100. M. Jugan, Program Manager, P. O. Box 2001, Oak Ridge, Tennessee 37831

101. W. A. Poulson, Jr., Senior Project Manager, Rust Remedial Services, Inc., 140 Stoneridge Drive, Columbia, South Carolina 29210

102. L. L. Radcliffe, Director, Waste Management and K-25 Operations Division, P. O. Box 2001, Oak Ridge, Tennessee 37831

103. R. C. Sleeman, Director, Environmental Restoration Division, P. O. Box 2001, Oak Ridge, Tennessee 37831

104. T. S. Tison, K-25 Site Manager, P. O. Box 2003, Oak Ridge, Tennessee 37830-7136

105-106. Office of Scientific and Technical Information, P.0. Box 62, 0ak Ridge, TN 37831 